LBL-31050

UC- 900

\title{
VHBORE: A Code to Compute Borehole Fluid Conductivity Profiles With Pressure Changes in the Borehole
}

\author{
F.V. Hale and C.F. Tsang \\ Earth Sciences Division \\ Lawrence Berkeley Laboratory \\ University of California \\ Berkeley, CA 94720
}

June 1994

This wark was carred out under U.S. Department of Energy Contract No. DE-AC03-76SF00098 for the Dinector, Office of Civilian Radjoactive Waste Management, Office of External Relations, administered by the Nevada Operations Ofince in conperation with the $S$ wiss National Conquerative for Dispostal of Radioactive Waste (Nagra). 


\section{DISCLAMER}

This report was prepared as an account of work sponsored by an agency of the United States Government. Neither the United States Government nor any apency thereof, nor any of their employees, make any warranty, express or implied, or assumes any legal liability or responsibility for the accuracy, completeness, of usefulness of any information, apparatus, product, or process disciosed, or represents that its use would not infringe privately owned rights. Reference hereln to any speciffc commerclal product, process, or service by trade neme, trademork, manufacturer, or otherwise does not necessarily constitute or imply its endorsement, recommerdation, or favoring by the United States Government or any agency thereof. The views and opinions of authors expressed herein do not necessarily state or reflect those of the United States Government or any agency thereof. 


\section{DISCLAIMER}

Portions of this document may be illegible in electronic image products. Images are produced from the best available origina! document. 
Table of Contents

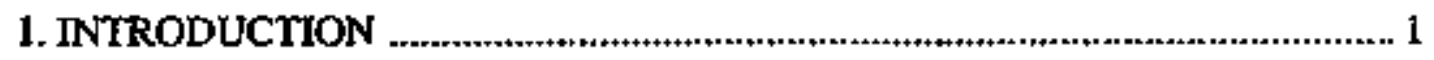

2. ANAL YTICAL AND NUMERICAL SOLUTIONS .................................. 2

3. DESCRIPTION OF FORTRAN CODE VHBORE ........................................ 11

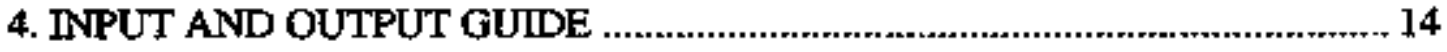

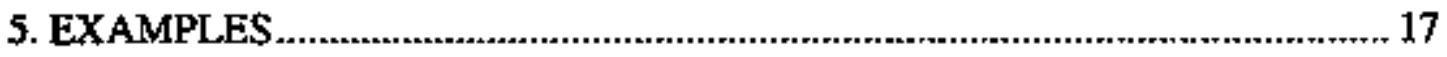

6. ACKNOWLEDGMENTS

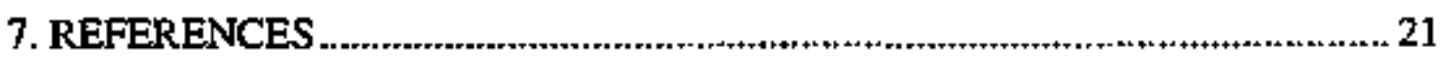

Figures

Appendix-*FORTRAN Source Code 


\section{INTRODUCTION}

This report describes the code VHBORE which can be used to model fuid electric conductivity profiles in a borehole intersecting fractured rock under conditions of changing pressure in the well bore. Pressure changes may be due to water level variations caused by pumping or fluid density effects as formation fluid is drawn into the bonehole. Previous reports describe the method of estimating the hydrologic behavior of fractured rock using a time series of electric conductivity logs (Tsang et al, 1989), and an earlier code, BORE, to generate electric conductivity logs under constant pressure and flow rate conditions (Hale and Tsang, 1988).

The earlier model, BORE, assumed a constant flow rate, $\mathrm{q}_{i}$, for each inflow into the well bore. In the present code the user supplies the location, constant pressure, $\mathrm{h}_{\mathrm{l}}$, transmissivity, $\mathbf{T}_{\mathbf{j}}$, and storativity, $\mathrm{S}_{\mathbf{1}}$, for each fracture, as well as the initial water level in the well. $h_{w}(0)$. In addition, the input data contains changes in the water level at later times, $\Delta h_{w}(t)$, typically caused by turning a pump on or off. The variable density calculation also requires input of the density of each of the inflow fluids, $\rho_{\mathrm{j}}$, and the intial uniform density of the well bore fluid, $p_{w}(0)$. These parameters are used to compute the flow rate for each inflow point at each time step.

The numerical method of Jacob and Lohman (1952) is used to compute the flow rate into or out of the fractures based on the changes in pressure in the wellbore. A dimensionless function relates flow rate as a function of time in response to an imposed pressure change. The principle of superposition is used to determine the net flow rate from a time series of pressure changes. Additional reading on the relationship between drawdown and flow rate can be found in Earlougher (1977), particularly his Section 4.6, "Constant-Pressure Flow Testing."

The primary difference between variable and constant density applications of the code is that with variable densities the pressure profile is computed at each time step, and when 
density variations in the well bore result in a significant pressure change (i.e. equal to a column of water of height equal to one half of the cell height, $\mathrm{pg \Delta x} / 2$ ), this is also added to the flow rate calculations. The wellbore is assumed to be vertical for purposes of pressure calculations; however no gravity-driven flow effects are considered in this code.

The electrolyte concentration and the density are not related in the present code. Therefore the code can be considered to model the transport of two independent substances using the same flow field. Only the electrolyte is affected by diffusion in the current code, and only the density affects the pressure profile. The decision to separate the density calculation from the electrolyte concentration was made to permit modeling of conditions where the density effects are due to something other than the electrolyte solutions, such as drilling mud. Full radial mixing is assumed in the cells, and fingering effects are not considered.

\section{NUMERICAL AND ANALYTTCAL SOLUTIONS}

\section{Governing Equation for Borehole Flow with Sources}

The differential equation for mass or solute transport in a borehole is:

$$
\frac{\partial}{\partial \mathrm{x}}\left(\mathbf{K} \frac{\partial \mathrm{C}}{\partial \mathrm{x}}\right)-\frac{\partial}{\partial \mathrm{x}}(\mathrm{CV})+\mathrm{S}=\frac{\partial \mathrm{C}}{\partial \mathrm{t}}
$$

where

$\mathrm{C}$ is the concentration $\left(\mathrm{kg} / \mathrm{m}^{3}\right)$

$\mathrm{K}$ is the dispersion coefficient $\left(\mathrm{m}^{2} / \mathrm{sec}\right)$

$\mathrm{S}$ is the source terin $\left(\mathrm{kg}^{\mathrm{m}} \mathrm{m}^{3}-\mathrm{sec}\right)$, and

$\mathrm{V}$ is the fluid velocity $(\mathrm{m} / \mathrm{sec})$

This partial differential equation is solved numerically using the firite difference method (FDM). The following initial and boundary conditions are also specified: 


$$
\begin{gathered}
C(x, 0)=C_{0}(x) \\
C\left(x>x_{\max }, t\right)=0 \\
K=0 \text { for } x>x_{\max } \text { or } x<x_{\text {min }}
\end{gathered}
$$

The first condition allows for the specification of initial electrolyte concentrations in the borehole. The second condition implies that there is no electrolyte in the borehole flenid flowing from below the area of interest. If there is a background concentration in the fluid flowing from the borehole bottom, this value should be added to all of the resulcing concentrations. The third condition indicates that dispersion does not take place across the specified boundaries of the area of interest. In general, advection will te the dominant process at the boundaries. If dispersion is dominant for a particular problem, the boundaries should be extended in order to prevent inproper trapping of electrolyte.

This is the same governing equation used by the constant flow code, BORE. The differences in VHBORE are seen in the source, velocity and, if velocity dependent, dispersion terms. The source tern, $S_{j}$, is no longer constant, but include the effects of two-way flow between the well bore and the formation as the pressure changes in the bonehole. The velocity term, $\mathrm{V}_{\bar{k}}$, varies in response to the pressure history of the well, and thus, if the dispersion coefficient, $\mathbf{K}_{\mathbf{i}}$, is velocity dependent, it will also vary continuously with time.

\section{Discretization in Space}

In the borehole, uniform, one-dimensional spacing of nodes is used. It is assumed that the borehole has uniform diameter $\mathrm{d}$, and that the region of interest is divided into $\mathrm{N}$ equal length cells of length $\Delta x$. Position values indicate depth in the borehole; thus $\mathrm{x}$ is zero at the surface and increases downward. The flow within the borehole is generally upward, and the cell index $i$ increases downstream (upward, toward the surface). Thus cells 1 and $\mathrm{N}$ are located at the bottom and top of the region, respectively, and node $\mathrm{x}_{\mathrm{i}}$ is 
upstrearn of and at a greater depth than node $x_{i+1}$. In general, node $i$ is located at $x_{\text {max }}-$ (i - 1/2) $\Delta x$, with boundaries of $x_{\max }-(\mathrm{i}-1) \Delta \mathrm{x}$ upstream (at a depth below the node), and $x_{\max }$ - (i) $\Delta x$ downstream (at a depth above the node). Note that because all cells are assumed to have the same geometry, flow rates are directly proportional to linear velocities.

Each inflow is given a specific location in the input file, and the inflows are then assigned to specific cells. If multiple inflows are assigned to the same cell, their flow rates and mass transfer rates are summed to produce a single source term for the cell. The single source for the cell is assumed to be located at the midpoint of the cell.

The BORE code modeled a fracture as an infinite source of fluid with zero concentration until a specified time, after which time the infinite source provides fluid with a constant concentration. In the codes described here, a set of 50 "buckets" of variable volume and concentration have been set hetween the borehole and this infinite fluid source of fixed concentration. These buckets represent no particular geometry, but rather just a volume of water with a particular concentration.

As fluid flows from the borehole to the fracture, the buckets are filled, one at each time step. In the code, this is accomplished by storing a volume and concentration in corresponding positions in the matrices VFRAC and CFZ, which are indexed by fracture and bucket. The volume and concentration of the flutd transfemed to the fractare depend on the time step, flow rate, and local borehole fluid concentration. It fluid has been flowing into the fracture for some time, and all of the buckets are full (i.e., all elements of the matrices VFRAC and CFZ for the fracture are in use), the oldest ten volumes are combined (i.e., dumped into one bucket, providing nine more empty buckets) by summing the volumes and computing a new concentration based on the total mass.

As fluid flows from the fracture zone to the borehole, the buckets are emptied in the reverse order. If all of the buckets are empty, fluid is drawn from the infinite sounce of 
constant concentration. If a number of buckets are necessary to meet the volume requirements for a single time step, the concentrations are averaged.

The user specifies an inieial volume and concentration in the first bucket There is no longer an initial period of zero concentration, rather fluid transfer between the borehole and the fracture begins inmediately. It is possible, however, to specify an intial volume of infiltrated water with a zero concentration.

The concentration of the fluid moving between the borehole and the fracture zone (in either direction) is deternined by subroutine CTFRAC which is executed at each time step. Subrouxine TSTEP computes the actual mass transfer from the borehole to the fracture zone.

\section{Discretization in Tirme}

Because the flow rates are not constant, a constant time step is not practical. Rather than having the user specify a time step, the subroutines FLOWS, DFLOWS, FLOWSA and TSTEP work together to compute a variable time step based on maximum veiocity and mass transfer rates. The time step is initially set by FLOWS or DFLOWS based on flow rates (velocities) in the previous time step, if possible. Then FLOWSA modifies the time step based on the expected flow rates during the present time step. If due to dispersion effects this time step results in mass transfer inconsistencies, the time step is further reduced by subroutine TSTEP.

\section{Methods of Computing the Dispersion Coefficient}

Within the code, three methods are available for decermining the dispersion coefficient for use at the interface between each pair of cells, $\mathrm{K}_{\text {i }} \mathrm{V} / 2$ : constant, velocity

scaled, and velocity squared scaled. The first approach is used to model dispersion due to molecular diffusion; the second, velocity dependence, is an approximation for porous medium transport; and the last, velocity-squared dependence, cortesponds to Taylor dispersion for flow in a pipe. With each method, the dispersion coefficients at the two 
adjacent cells to an interface are computed, then the harmonic mean is used at the interface. Because no dispersion occurs across the region boundaries, $\mathrm{K}_{1 / 2}$ and $\mathrm{K}_{\mathrm{N}+1 / 2}$ are defined to be zero.

With the constant method, the input dispersion parameter, $\mathrm{K}_{0}$, is used for all the cell interfaces and Equation (1) simplifies to

$$
\mathbf{K}_{0} \frac{\partial^{2} \mathrm{C}}{\partial \mathrm{x}^{2}}-\frac{\partial}{\partial \mathrm{x}}(\mathrm{CV})+\mathrm{S}=\frac{\partial \mathrm{C}}{\partial \mathrm{t}}
$$

The velocity scaled methods use a somewhat arbitrary reference dispersion coefficient $\mathrm{K}_{\mathrm{O}}$ defined as the dispersion coefficient at a depth where the flow velocity is equal to the mean velocity or the mean velocity squared,

$$
\overline{\mathrm{V}}^{\bar{n}}=\frac{\min \left(\mathrm{V}_{1}^{\mathrm{n}}\right)+\max \left(\mathrm{V}_{2}^{\mathrm{a}}\right)}{2}
$$

where $V_{j}^{n}$ is the fluid flow velocity at node $i$ russed to the first or second power ( $n=1$ or 2). Then the dispersion coefficient for node $i$ is given by

$$
K_{i}=K_{0}\left(\frac{V_{i}^{n}}{\bar{V}^{\bar{n}}}\right) \text {. }
$$

Note that since the cells have a uniform volume the velocities are proportional to the flow rates, and the actual calculations are based on $q_{i}$ rather than $v_{i}$ (since $q_{i}=v_{i} A_{\text {, }}$ where $A$ is the uniform cross-sectional area).

The dispersion coefficient at the interface between two cells is the harmonic mean:

$$
K_{ \pm \pm 1 / 2}=1\left(\frac{1}{K_{i}}+\frac{1}{k_{i} \pm I}\right)^{-1}
$$

For cells with no flow (e.g., upstrearn from the first feed point), the dispersion coefficient of the trst cell with nonzero flow is used.

The dispersion coefficients are then adjusted for the problem geometry, 


$$
\gamma_{\mathrm{i}+1 / 2}=\frac{A K_{\mathrm{i}+1 / 2}}{\Delta \mathrm{x}}
$$

where $A$ is the uniform cross-sectional area.

If the dispersion type is flow rate dependent (ITYPDK is 2 or 3 ), the dispersion coefficients must be computed during each time step. This is done in subroutine FLOWSA after the current flow rates and velocities have been computed by subroutines FLOWS or DFLOWS.

\section{Calculation of Flow Rates}

At a given time the flow rate from a fracture zone to the borehole (or from the borehole to the fracture zone) is a function of the fracture zone hydraulic parameters and the pressure history in the borehole. At each time step the flow rate is computed by a superposition of the effects of individual pressure changes. This calculation is performed in subroutine FLOWS for constant density calculations and by subroutine DFLOWS for variable density calculations.

The effect of a single pressure change, $j$, for a single inflow, $i$, is computed using a dimensionless function, $\mathrm{gD}$, which is defined as follows:

$$
q_{i, j}(t)=2 \pi T_{j} \Delta h_{j} q_{D}\left(t_{D}(t)\right)
$$

where

$$
t_{D}(t)=\left(\frac{T_{i}\left(t-\tau_{j}\right)}{S_{i} r^{2}}\right)
$$

where $T_{i}$ is the transmissivity of the inflow, $S_{j}$ is the storativity of the inflow, $r$ is the well bore radius, $\Delta h_{j}$ is the drawdown for pressure change $j_{j}$ and $\tau_{j}$ is the time of pressure change $\mathrm{j}$.

In these codes, the terms $2 \pi \mathrm{T}_{\mathrm{i}}$ and $\mathrm{T} ; / \mathrm{S}_{\mathrm{i} 2} 2$ are calculated in subroutine RDFRAC and stored as $Q C O E F(I)$ and TCOEF(D, respectively. The dimensionless function $q D$ is 
computed using linear interpolation on a table for arguments valpes between $10^{-4}$ and 1012. The table is from Jacob and Lohman (1952). For dimensionless times (tD) greater than $10^{12}$, Earlougher (1977) suggests using $\mathrm{qD}=2 /(\mathrm{ln}(\mathrm{tD})+0.80907)$. For values below $10^{-4}$, a somewhat arbitrary constant value of 56.9 is used (this is the value for dimensionless time $10^{-4}$ given by Jacob and Lohman). Figure 1 shows the graph of the function $\mathrm{qD}$.

The calculation of flow rates is more complex for variatle density cases. As the fluid of different densities enters the well bore, the pressure profile in the well bore changes. The pressure is no longer just a function of the drawdown values specified in the input file, but also of the changing density profile in the well. At any given time, the pressire (in meters of water) can be calculated as:

$$
p_{i}(t)=\frac{1}{\rho_{w}} \int_{x_{w}}^{x_{j}} \rho(x, t) d x
$$

where $\rho_{w}$ is the density of water, $g$ is the acceleration due to gravity, and $x_{w}$ is the depth of the water surface.

The use of the Jacob-Lohman solution requires that at every time step following a pressure change the effect of the pressure change be computed. In order to provide for some reasonable number of pressure changes to be recorted during the run, the wellbore pressure at each inflow in discretized in time. If a pressure change at an inflow exceeds one half of a cell length, it is considered significant, recorded, and affects all following flow rate calculations. All of the is done in subroutine DFLOWS. The array PHIST stores the pressure history (pressure and time) for each inflow. Stated more concisely, the current criterion for recording a significant pressure change due to density is:

$$
\left|\mathrm{p}_{\mathrm{i}}\left(\mathrm{t}_{1}\right)-\mathrm{p}_{\mathrm{i}}\left(\mathrm{t}_{2}\right)\right|>\Delta \mathrm{x} / 2
$$


This condition make the assumption that the water level, $\mathrm{x}_{\mathrm{w}}$, does not change between times $t_{1}$ and $t_{2}$.

After the flows between the fracture zones and the borehole have been deternined, the flow rates in the remaining cells are computed by subroutine FLOWSA assuming a closed lower boundary and open upper boundary in the borehole, using the discretized version of Equation (1).

Note that if the input value for the initial drawdown and inflow depths and pressure heads results in pressure differences between the input values for the fractures, it is assumed that this pressure change took place at the model staring time (TSTART).

\section{Calculation During Each Time Step}

The constant mass injection of BORE has been replaced in the variable pressure codes by possible two-way mass transfer between the borehole and the fractures. At each time step the flow rate (and direction) and fluid concentration for transfer between the borehole and the fracture zones is computed. This has been described above.

The mass transfer within the borehole during time step $\mathrm{k}$ is due to flow to or from the feed points (the source of electrolyte), advection, and dispersion. The finite-difference version of Equation (1) may be written in terms of mass transfer ( $\mathrm{kg} / \mathrm{sec}$ ) as follows:

$$
\begin{aligned}
\left(\Delta \mathrm{C}_{\mathrm{i}, \mathrm{k}} / \Delta \mathrm{t}\right)(\mathrm{A} \Delta \mathrm{x})= & \mathrm{C}_{\mathrm{i}, \mathrm{k}}^{\mathrm{f}}\left(\mathrm{q}_{\mathrm{i}}^{\mathrm{f}}\right) \\
& +\mathrm{C}_{\mathrm{j}-1, \mathrm{k}-\mathrm{k}}\left(\mathrm{q}_{\mathrm{i}-1 / 2}\right)-\mathrm{C}_{\mathrm{i}, \mathrm{k}-1}\left(\mathrm{q}_{\mathrm{i}+\mathrm{i} / 2}\right) \\
& +\left(\mathrm{C}_{\mathrm{i}-1, \mathrm{k}-1}-\mathrm{C}_{\mathrm{i}, \mathrm{k}-1}\right)\left(\gamma_{\mathrm{i}-1 / 2}\right)-\left(\mathrm{C}_{\mathrm{i}, \mathrm{k}-\mathrm{l}}-\mathrm{C}_{\mathrm{i}+\mathrm{l}, \mathrm{k}-\mathrm{i}}\right)\left(\gamma_{\mathrm{i}+1 / 2}\right)
\end{aligned}
$$

where $C_{i, k}^{f}$ is the average concentration of electrolyte in the fluid flowing from the feed points into cell $\mathrm{i}$ during time step $\mathrm{k}$, and $\gamma_{\mathrm{i} \pm} \mathrm{l} / 2$ is the dispersion coefficient at the interface between two adjoining cells adjusted for the problem geometry. The first line of the right-hand side is the source term, the second line is the advection term, and the third line is the dispersion term. Upstream weighting is used in the advective terms. 
This equation can be rewritten by collecting coefticients of the different cell concentrations as:

$$
\begin{aligned}
\left(\Delta C_{i, k} / \Delta t\right)(A \Delta x)= & C_{i, k}^{f}\left(q_{i}^{f}\right) \\
& +C_{i-1, k-1}\left(q_{i-1 / 2}+\gamma_{i-1 / 2}\right) \\
& +\left(C_{i, k-1}\left(-q_{i+i / 2}-\gamma_{i-1 / 2}-\gamma_{i+1 / 2}\right)\right. \\
& +C_{i+1, k-1}\left(\gamma_{i+1 / 2}\right)
\end{aligned}
$$

At each time step $\mathrm{k}$ a check is made to verify that the total mass in the cell at the beginning of the time step is greater than or equal to the lotal mass to be transported out of the cell during the time step. If this condition is not met, an error message is printed and the time step is reduced.

Conservation of mass is verifted during each time step and at the end of the problem. Mass may flow into the system from the infinite reservoir in each fracture zone, and mass may flow out of the system at the top of the borehole section. All other boundaries are ciosed.

\section{Temperature Dependence of Conductivity}

All calculations are made assuming a unil\%tom temperature of $20^{\circ} \mathrm{C}$ throughout the borehole. Generally temperature increases with depth below the land surface, so temperature corsections must be applied to field conductivity data to permit direct comparison with model output.

The effect of temperature on conductivity can be estimated using the following equation from NAGRA (1987):

$$
\sigma\left(20^{\circ} \mathrm{C}\right)=\frac{\sigma\left(\mathrm{T}_{\mathrm{x}}\right)}{1+S\left(\mathrm{~T}_{\mathrm{x}}-20^{\circ} \mathrm{C}\right)}
$$

where $T_{x}$ is the temperature $\left({ }^{\circ} \mathrm{C}\right)$ at depth $\mathrm{x}$. The value of $\mathrm{S}$ is estimated at 0.022 . 


\section{Conductivity as a Function of Concentration}

Assuming that all of the ions in the borehole fluid can be converted to $\mathrm{NaCl}$ equivalents, the conductivity and concentration data in Shedlovsky and Shedlovsky (1971) can be fit fairly well using a quadratic approximation:

$$
\sigma=2,075 \mathrm{C}-45 \mathrm{C}^{2}
$$

where $\mathrm{C}$ is the concentration in $\mathrm{kg} / \mathrm{fm}^{3}$ and $\sigma$ is the conductivity in $\mu \mathrm{S} / \mathrm{cm}$ at $25^{\circ} \mathrm{C}$. The expression is accurate for a range of $C$ up to $5 \mathrm{~kg} / \mathrm{m}^{3}$ and $\sigma$ up to $10,000 \mu \mathrm{S} / \mathrm{cm}$. For even lower $C$ up to $1 \mathrm{~kg} /\left\{\mathrm{m}^{3}\right\}$ and $\sigma$ up to $0.2 \mu \mathrm{S} / \mathrm{cm}$, the second term may be neglected.

Although the experimental values are for $25^{\circ} \mathrm{C}$, they may be used at $20^{\circ} \mathrm{C}$ if multiplied by 0.89 (hased on Equation (14) for the temperature dependence of conductivity). Thus the above relationship would be

$$
\sigma=1,850 \mathrm{C}-40 \mathrm{c}^{2} \text {. }
$$

\section{DESCRIPTION OF FORTRAN CODE VHBORE}

The main program is little more than a single time step loop and a series of subroutine calls. Before the time step loop begins, a single call to the subroutine INITS is made to initialize all data areas and read the problem descriptions. Within the time step loop, the flow rates are first computed using either constamt or variable density approaches (using etther subroutine FLOWS or subroutine DFLOWS). Once the flow rates are computed, a time step size is determined, and the mass transfer for the tine step is accomplished using subroutine ONESTEP. If the time step was determined to be too large (too much mass was transferred out of a cell), the time step is reduced and the flow rates and mass transfer are preformed again. If the time step was successful, the subroutine GOODSTEP is called to check for output requests. After the ending time has been reached, a single call to the subroutine ENDPROB is made to produce the final messages regarding mass transfer. 


\section{Common Blocks}

The program has four named comrnon blocks, CORR, FRACS, SEGS and STEP which are defined in a separate source code file, VPCOMMS.F, and included as needed in the main source file. The common block source file uses a set of parameters to specify array sizes, making it easier to change array sizes as need to suit different problems and computing environments.

Common block CORR contains the coefficients for converting electrolyte concentration in $\mathrm{kg} / \mathrm{m}^{3}$ to conductivity in $\mu \mathrm{S} / \mathrm{cm}$. These terms are derived from a second degree polynomial fit to experimental data, and are read by subroutine RDCORR.

Common block FRACS contains the arrays describing the fractures, including the fracture flow rates, concentrations, positions, segment locations, transmissivities, storativities, infiltration volumes, fluid densities, etc.

Common block SEGS contains the arrays describing each segment, including the concentration and density at the beginning and end of the time step, the fracture inflow average concentration and density, external flows into and out of the segment, fracture flow into the segment, downstream flow to the next segment, total flow into the segment, the position of the segment and the dispersion coefficient between the segment and the next downstream segment.

Common block STEP contains other variables used during the time steps, including the step duration, number of segments, maximum number of segments allowed, uniform segment voltme, cumulative mass and volume out of the system, cumulative mass and volume into the system, time at the beginning and end of the time step, number of fractures, conductivity output unit number, toggle index for the concentration array, etc.

\section{Subroutines and Functions}

The first level of subroutines includes INTTS, FLOWS, DFLOWS, ONESTEP, GOODSTEP and ENDPROB. These subroutines are called by the main program. 
INITS performs global variable initialization, opens the isput and output files, reads the problem definition input file and perfotms the initial mass halance using subroutine SMASS.

The two main portions of the the time step loop compute the variable flow rates and perform the mass transfer. For a constant density calculation, the variable flow rates are determined by subroutine FLOWS; while for a variable density case, the subroutine DLFLOWS is used. The primary difference between these two routines is that FLOWS using only depth to determine pressure differences (assuming a constant density fluid in the well bore, whereas DFLOWS performs an actual integration of the density of all well bore fluid in order to detemine the pressure at some depth. Both subroutines use the function QD to determine individual inflow rates using the Jacob-Lohman solution, atsd, after the individual inflow rates have been determined, both subroutines also call the subroutine FLOWSA to develop the full flow rate profile, estimate the time step size, and determine any velocity dependent aspects of the calculation.

The mass transfer for a single time step is carried out by subroutine ONESTEP. This subroutine advances the simulation clock, save current state variables in case the time step must be reversed, and calls subroutines CTFRAC and TSTEP. Subroutine CTFRAC determines the average concentration and density of the source terms for the time step based on the inflow rates, the time step, and any storage of fluid in the intlow zones. Subroutine TSTEP peforms the actual mass transfer calculation and checks for conservation of mass. If the subroutine TSTEP indicates that an attempt was made to transfer too much mass out of a cell during the time step (due to the combined effects of advection and diffusion), a flag is set and the time step is reduced.

As mentioned atove, the subroutine GOODSTEP is called if the time step was successful in order to determine if any output has been requested following the current time step. Actual output of conductivity profiles is produced by subroutine CPRT. 
At the end of the computation, the subroutine ENDPROB is called to produce a number of infomational messages about the calculation.

\section{INPUT AND OUTPUT GUIDE}

\section{Inpert and Output Füles}

The model uses one input and four output files. The input file contains the problem description consisting of borehole geometry, top and botton bonehole flows, feed point flows, timing parameters, dispersion parameters, and initial concencrations. The output files consist of (1) messages produced by the model, (2) conductivity-depth pairs for each borehole cell at the requested output times, (3) flow rate-depth pairs for each cell at the requested output tines, and (4) density-depth pairs for each cell at the nequested output times, The following tatle summarizes the input and output files and indicates their FORTRAN unit numbers.

Table 4-1. Input and Output Files

\begin{tabular}{lll}
\hline UNIT NUMBER & INPUT/OUTPUT & DESCRIPTION \\
\hline 5 & INPUT & Problem description \\
6 & OUTPUT & Messages \\
7 & OUTPUT & computed conductivity \\
8 & OUTPUT & Flow rate profile \\
9 & OUTPUT & Density profile \\
\hline
\end{tabular}

\section{Problem Description}

The problem description is entered in free formut, with values being separated by spaces or commas. The number of lines in the problem description will he variable depending on the number of feed points, number of times at which conductivity output is 
desired, and number of initial concentrations specified. The following table provides a detailed description of each line of the input.

Table 4-2. Input Guide.

\begin{tabular}{|c|c|c|c|}
\hline LINE & NAME & UNITS & DESCRIPTION \\
\hline \multirow[t]{6}{*}{1} & XTOP & $\mathbf{m}$ & $\begin{array}{l}\text { Top of study area, sutface is zero and } \\
\text { positions increase downward, adjusted } \\
\text { if necessary to fit XBOT and DELXX }\end{array}$ \\
\hline & XBOT & m & Bottom of study area \\
\hline & DELX & m & Cell length \\
\hline & DIAM & $\mathrm{cm}$ & Borehole diameter (uniform) \\
\hline & WATLEV & & Lnitial water level in well \\
\hline & TOPD & none & $\begin{array}{l}\text { Initial density of well bore fluid } \\
\text { nomalizedhy density of water (spec. } \\
\text { grav.). TOPD } \leq 0 \text { for constant density } \\
\text { calculation }\end{array}$ \\
\hline \multirow{8}{*}{21} & FELM & none & Number of inflows \\
\hline & XIN(I) & $\mathrm{m}$ & Position of inflow \\
\hline & $\operatorname{CIN}(\mathrm{L}, 1)$ & $\mathrm{kg} / \mathrm{m}^{3}$ & $\begin{array}{l}\text { Constant concentration for formation } \\
\text { water }\end{array}$ \\
\hline & $\begin{array}{l}\text { TFRAC(I) } \\
\text { SFRAC(I) }\end{array}$ & $\mathrm{m}^{2} / \mathrm{sec}$ & $\begin{array}{l}\text { Inflow transmissivity } \\
\text { Inflow storativity }\end{array}$ \\
\hline & HFRAC(I) & & Inflow pressure (over $\rho g$ ) \\
\hline & & & $\begin{array}{l}\text { Inflow initial volume of infiltrated } \\
\text { deionized water }\end{array}$ \\
\hline & CFZ(I,1,1) & $\mathrm{kg} / \mathrm{m}^{3}$ & Infiltrated water concentration \\
\hline & CIN(I,2) & none & $\begin{array}{l}\text { Density of inflow fluid normalized by } \\
\text { density of water (spec. grav.) (only for } \\
\text { variable density calculation) }\end{array}$ \\
\hline
\end{tabular}


Table 4-2, Continued.

\begin{tabular}{|c|c|c|c|}
\hline $\begin{array}{l}3 \\
3 I\end{array}$ & $\begin{array}{l}\text { IDHLIM } \\
\text { DELHT(I) }\end{array}$ & $\begin{array}{l}\text { none } \\
\text { hr }\end{array}$ & $\begin{array}{l}\text { Number of water level changes } \\
\text { Time at which water level in horehole } \\
\text { changes }\end{array}$ \\
\hline I-1,IDHLIM & . DELLHH(I) & $\mathrm{m}$ & Change in water level (positive down) \\
\hline$\underset{I=1, I L P T}{4 I}$ & $\begin{array}{l}\text { TSTART } \\
\text { TEND } \\
\text { TSMAX } \\
\text { ILPT } \\
\text { PT(I) }\end{array}$ & $\begin{array}{l}\text { lin } \\
\mathbf{H} \\
\min \\
\mathrm{lr}\end{array}$ & $\begin{array}{l}\text { Problem start time } \\
\text { Problem end time } \\
\text { Maximum time step } \\
\text { Number of print times } \\
\text { Time to print profile }\end{array}$ \\
\hline 5 & ITYPDK & $\mathrm{m}^{2 / \mathrm{sec}}$ & 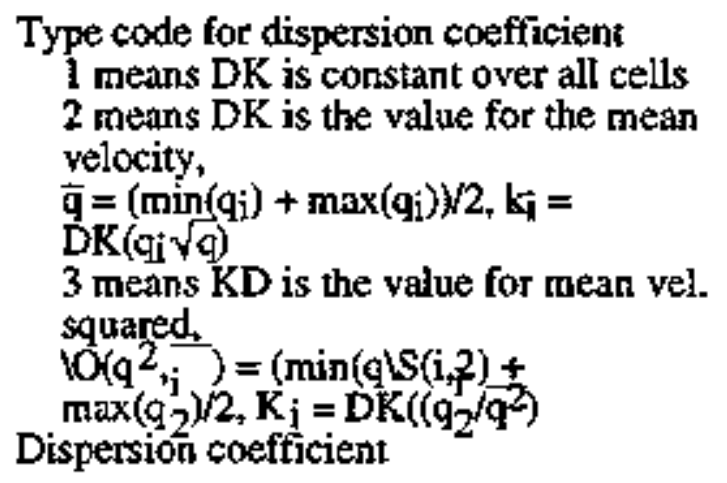 \\
\hline $\begin{array}{l}6 \\
6 . \mathrm{I} \\
\mathrm{I}=1, \mathrm{ICON}\end{array}$ & $\begin{array}{l}I C O N \\
X(I) \\
C O(I) \\
D O(I)\end{array}$ & $\begin{array}{l}\text { none } \\
\text { ming } \\
\text { kg/m } 3 \\
\text { none }\end{array}$ & $\begin{array}{l}\text { Number of initial concentrations } \\
\text { Position of initial concentration } \\
\text { Initial concentration } \\
\text { Initial density, normalized by density of } \\
\text { water (spec. grav.) (only for variable } \\
\text { density crlculation) }\end{array}$ \\
\hline 7 & $\begin{array}{l}\text { COEFA } \\
\text { COEFB }\end{array}$ & $\begin{array}{l}\left(1 / \mathrm{S} \cdot \mathrm{m}^{2}\right) / 100 \\
\mathrm{~kg} \\
\left(\mathrm{i} \mathrm{S}^{2} \cdot \mathrm{m}^{5}\right) / 1000 \\
\mathrm{~kg}^{2}\end{array}$ & $\begin{array}{l}\text { constant term for converting } \\
\text { concentration in } \mathrm{kg}^{\prime} \mathrm{m}^{3} \text { to conductivity } \\
\text { in } \mu \mathrm{S} / \mathrm{cm} \\
\text { linear ceofficient for converting } \\
\text { concentration to conductivity } \\
\text { quadratic coefficient for converting } \\
\text { concentration to conductivity }\end{array}$ \\
\hline
\end{tabular}

The output subroutine CPRT converts concentration to conductivity just prior to output by means of the coefficients in common CORR. If the coefficients $0,1,0$ are entered, then the output valuxs are equivalent to the concentrations. The output subroutine CPRT also converts flow rates to liters per minute just prior to output. 


\section{EXAMPLES}

\section{Verification Example: Single inflow, single pressure change}

The first example allows verification by comparing with Example 4.4 in Earlougher (1977). A single pressure change is applied to a single inflow. Earlougher's example refers to an inflow zone of length 57.9 meters; this will be represented in two different ways, both as a single inflow and as as a set of 58 inflows with a cell length of one meter. The example applies a pressure drop of 703.6 meters ( $1000 \mathrm{psi}$ ). The hydrological characteristics include a permeability of 6.5 millidarcy and a viscosity of 1.35 centipoise. giving a trensmissivity of $2.697 \times 10^{-6} \mathrm{~m}^{2} / \mathrm{sec}$. The porosity $\sim$ compressibility product is

$2.05 \times 10^{-6} \mathrm{j} \mathrm{psi}^{-1}$, giving a storativity of $168.7 \times 10^{-6}$. The single drawdown occurs at time zero hours.

The input for this eximple problem with the inflow represented as a single point is shown below.

\begin{tabular}{ll} 
LINE & DATA \\
\hline 1 & $000,2000,1,60.96,0,-1$ \\
2 & $1000.1 .002 .697 \mathrm{e}-6$ 168.7e-6 1899.50.0. \\
2.1 & 1 \\
3 & 0703.57 \\
3.1 & $0,100,15,9$ \\
4 & 0.2 \\
4.1 & 0.5 \\
4.2 & 1 \\
4.3 & 2 \\
4.4 & 5 \\
4.5 & 10 \\
4.6 & 20 \\
4.7 & 50 \\
4.8 & 100 \\
4.9 & $1,0.5 \mathrm{e}-3$ \\
5 & 0 \\
6 & $73 ., 1870 .,-40$. \\
7 &
\end{tabular}

The input for the case of 58 inflows is identical to that above except for lines 2 and 2.x. The transmissivity and storativity values have been scaled by 58 : 


\begin{tabular}{|c|c|}
\hline LINE & DATA \\
\hline $\begin{array}{l}2 \\
2.1\end{array}$ & $\begin{array}{l}58 \\
1900.1 .0046 .495 e-92.9092 \mathrm{e}-61899.50 . \\
0 .\end{array}$ \\
\hline 2.2 & $\begin{array}{l}1901.1 .0046 .495 \mathrm{e}-92.9092 \mathrm{e}-61900.50 . \\
0 .\end{array}$ \\
\hline $\begin{array}{l}2.3 \text { to } 57 \\
2.58\end{array}$ & $\begin{array}{l}\text { (omitted) } \\
1957.1 .0046 .495 \mathrm{e}-92.9092 \mathrm{e}-61956.50 . \\
0 .\end{array}$ \\
\hline
\end{tabular}

The negative value at the end of the first line of the input indicates a constant density calculation. Both approaches to the inflow description result in the same number of simulation time steps $(5,415)$, ranging from 7.8 to 73 seconds.

Figures 2 through 6 illustrate different aspects of the calculation. Figure 2 shows the flow rate as a function of time. The units are Earlougher's oil-field system of barrels per day (one liter per minute is 9.0573 barrels per day). This figure matches Figure 4.13 in Earlougher (1977). The flow rate is the same regardless of which representation of the inflow zone is used.

The flow rate and conductivity profiles for the single point representation are shown in Figures 3 and 4 , and Figure 5 and 6 show the same for the 58-cell representation. The different approaches to modeling the inflow section have fairly limited effects. The flow rate shows a ramp for the line source, as opposed to a step for the point source, and there is a slower buildup of saturated concentration levels with the line source.

\section{Variable Density Examples}

In order to demonstrate the effect of well bore fluid density on the flow rate, two variations on the above single inflow, single pressure drop case are presented here. In the first, the well bore fluid is twice as dense as the inflow fluid; and, in the second case, the inflow fluid is twice as dense as the well bore fluid. The changes in the input file are shown below: 


\begin{tabular}{|c|c|}
\hline LINE & DATA \\
\hline $\begin{array}{l}1 \\
2 \\
2.1\end{array}$ & $\begin{array}{l}1000,2000,1,60.96,0,2 \text { [well bore fluid } \\
\text { density high] } \\
1 \\
1900.1 .002 .697 \mathrm{e}-6168.7 \mathrm{e}-6 \text { 1899.5 0. 0. 1. } 0 \text {. }\end{array}$ \\
\hline LINE & DATA \\
\hline $\begin{array}{l}1 \\
2 \\
2.1\end{array}$ & $\begin{array}{l}1000,2000,1,60.96,0,1 \\
1 \\
1900,1.002 .697 \mathrm{e}-6168.7 \mathrm{e}-61899.50 .0 .2 .0 . \\
\text { [denity high] }\end{array}$ \\
\hline
\end{tabular}

Figures 7 and 8 show the flow rate as a function time for these two cases. In Figure 7, with the well bore fluid having a higher density, the pressure difference between the inflow and the well bore at the inflow depth is initially reduced, so the flow rate is also reduced. As the less dense fluid flows into the well bore and the denser fluid is pumped out, the pressure difference at the inflow depth increases, until, after about 30 hours the denser fluid initially in the weil bore has teen flushed out, and the problem converges with the constant density solution.

In Figure 8, with the inflow fluid having a higher density, the flow rate is initially similar to the constant density case. But as the denser fluid flows into the well, driving up the pressure at the inflow depth, the flow rate decreases. Eventually, after a few hundred hours, the flow stops since even with the drawdown of over 700 meters, the denser fluid in the well bore has resulted in equilibrium between the well and the inflow at the inflow depth.

Figure 9 shows the driving pressure differences in meters of water as a function of time for these cases.

\section{Multiple Inflow, Multiple Pressure Change}

One more complex example is presented which involves three inflows and two drawdown changes. The problem is a variation of the constanst density verification 
example at the start of this section. The inflow and drawdown change input is as follows: shown below:

\begin{tabular}{|c|c|}
\hline LINE & DATA \\
\hline $\begin{array}{l}2 \\
2.1 \\
2.2 \\
2.3 \\
3 \\
3.1 \\
3.1\end{array}$ & 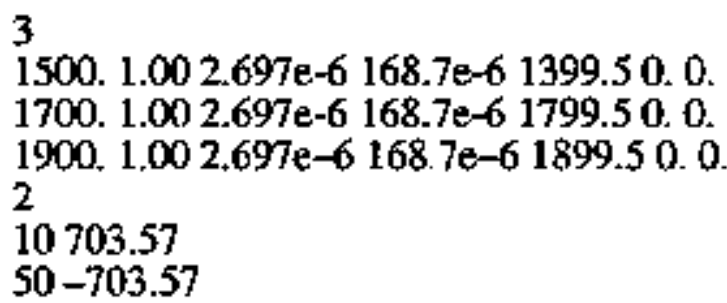 \\
\hline
\end{tabular}

Notice that when the water level is at the surface, there is a circulation within the well from 1700 meters to 1500 meters due to inflow pressure head differences. The water level changes approximate turning a pump on at 10 hours and off at 50 hours.

Figure 10 shows the flow rate across the inflow at 1500 meters as a function of time. Note that initially the flow is negative, i.e. water is flowing from the wellbore into the formation. Figure 11 shows the concentration of the waler fowing across the inflow.

Figures 12 and 13 show the flow rate and conductivity profiles for the entire wellbore at times before, during and after pumping.

\section{ACKNOWLEDGEMENTS}

Discussions and comperation with NAGRA personnel, especially S. Vomvoris and $\mathbf{P}$. Bluemling are much appreciated. We would also like to thank Christine Doughty of LBL for reviewing and commenting on the manuscript and soltware. This work was carried out under U.S. Department of Energy Contract No. DE-AC03-76SF00098 for the Director, Office of Civilian Radioactive Waste Managemen, Office of Extemal Relations, administered by the Nevada Operations Office in cooperation with the Swiss National Cooperative for Disposal of Radioactive Waste (Nagra). 


\section{REFERENCES}

Earlougher, R.C. (1977), "Advances in Well Test Analysis," Society of Petroleum Engineers, New York.

Hale, F.V, and C.F. Tsang (1988), "A code to compute borehole fluid conductivity profiles with multiple feed points," LBL-24928, Lawtence Berkeley Laboratory, University of Calfformia, and NDC-2, NAGRA, Baden, Switzerland.

Jacob, C.E. and S.W. Lohman (1952), "Nonstendy flow to a well of constant drawdown in an extensive aquifer," Transactions, American Geophysical Union, v. 33, no. 4, pp. 559-569.

NAGRA (1987). Private communication from Dr. Peter Hufschmied, NAGRA, Baden, Switzerand.

Shedlovsky, T. and L. Shedlovsky (1984), Conductometry, in Techniques of Chemistry, Vol 1: Physical Methods of Chemistry, Part IIA: Electrochemical Methods A. Wejssberger, ed., Wiley-Interscience, New York, 1971.

Tsang, C.F., P. Hufschmied and F.V. Hale (1989), "Determination of fracture inflow parameters with a borehole fluid conductivity logging method," Water Resources Research, v. 26 (1990), no. 4. pp. 561-578, and LBL-24752, Lawrence Berkeley Laboratory. University of California, and NDC.1, NAGRA, Baden Swizzerand. 



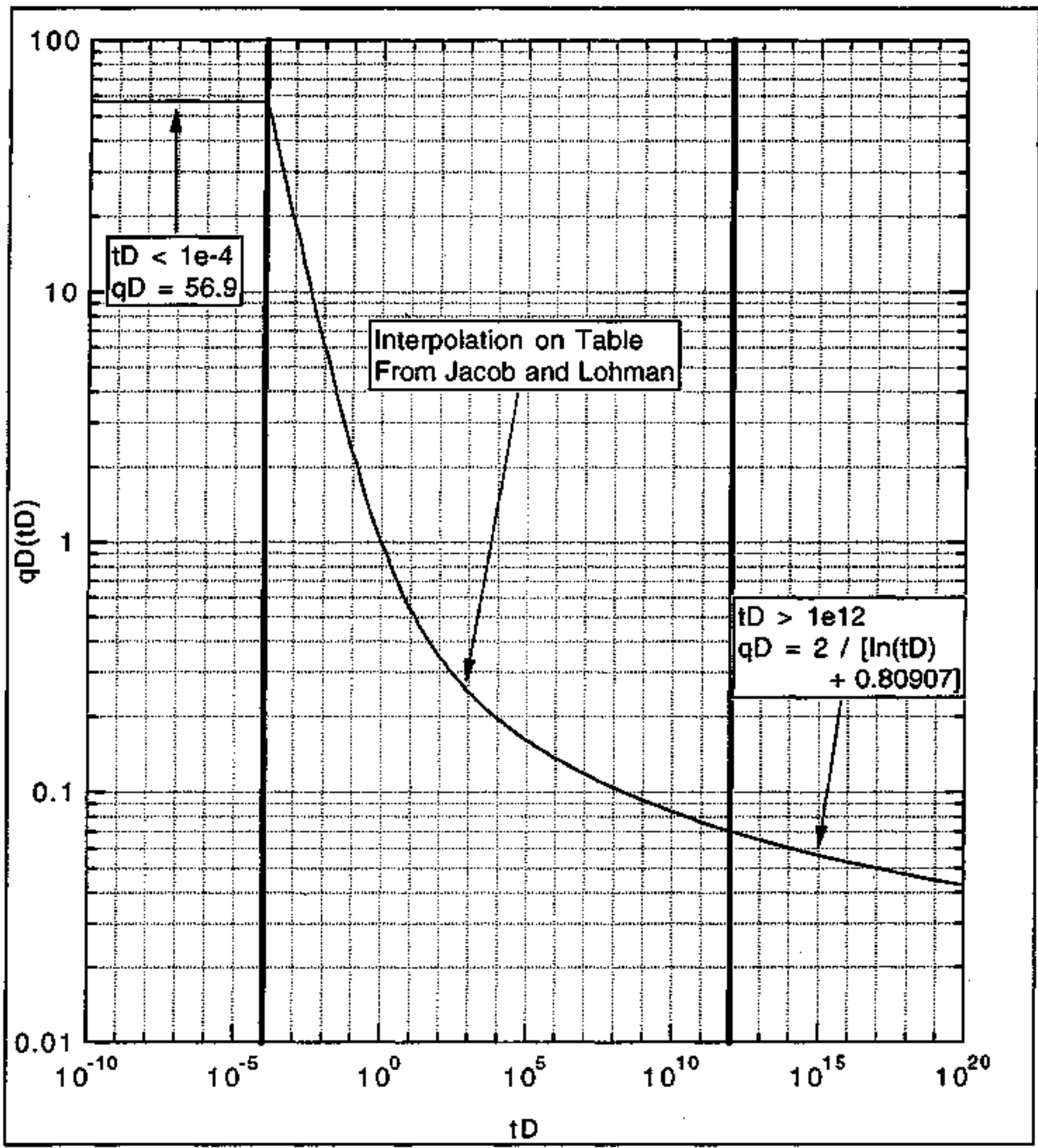

Figure 1. Dimensionless flow rate as a function of dimensionless time, showing the three solution techniques used in different subdomalns. 


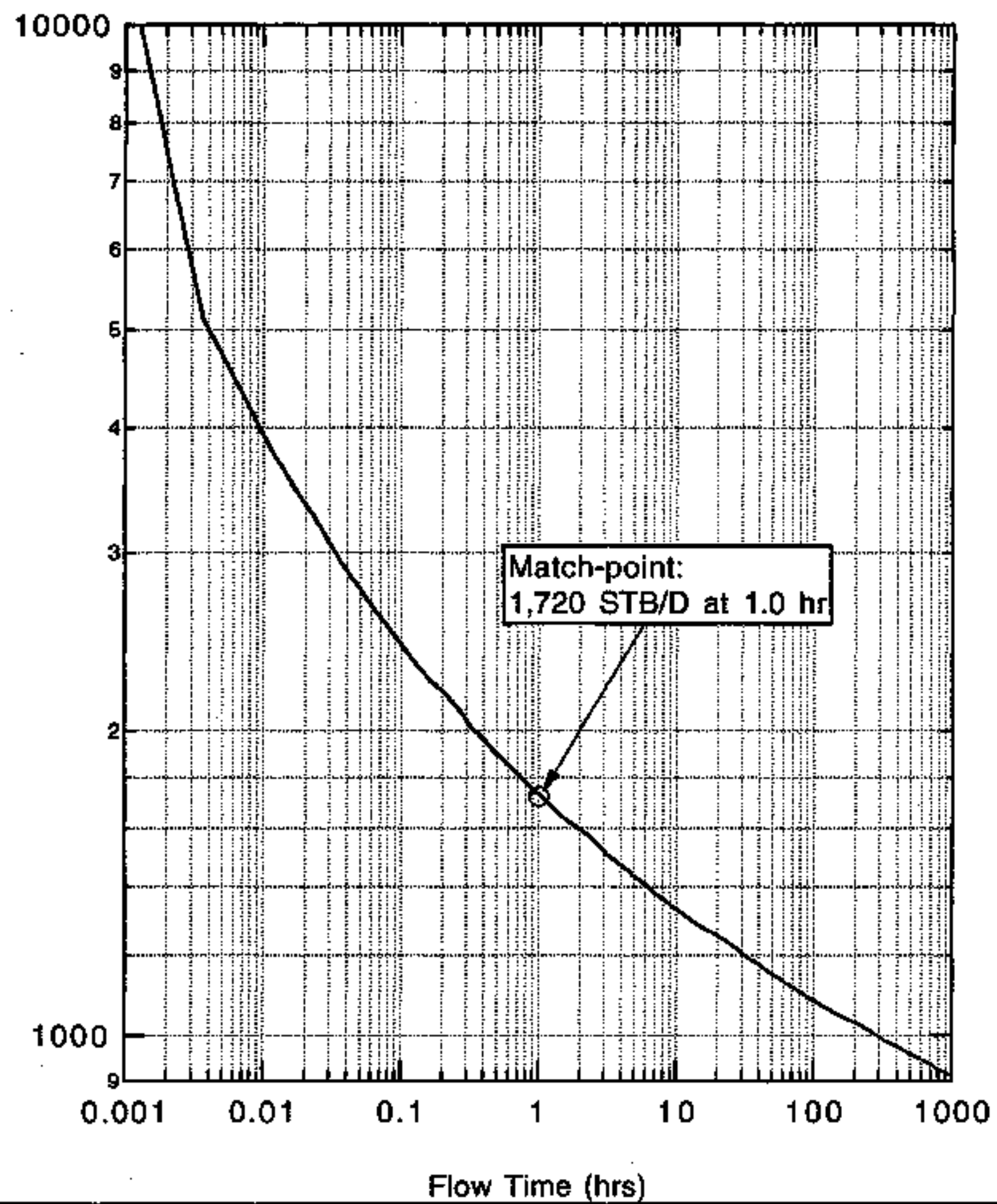

Figure 2. Flow rate as a function of time for $T=2.697 \theta-6 \mathrm{~m}^{\star} \mathrm{m} / \mathrm{s}$. $\mathrm{S}=168.7 \theta-6$, drawdown of 703.57 meters. Matches Figure 4.13 in Earlougher (1977) for example of constant-pressure testing in an infinite-acting reservoir (Earlougher's Example 4.4). 


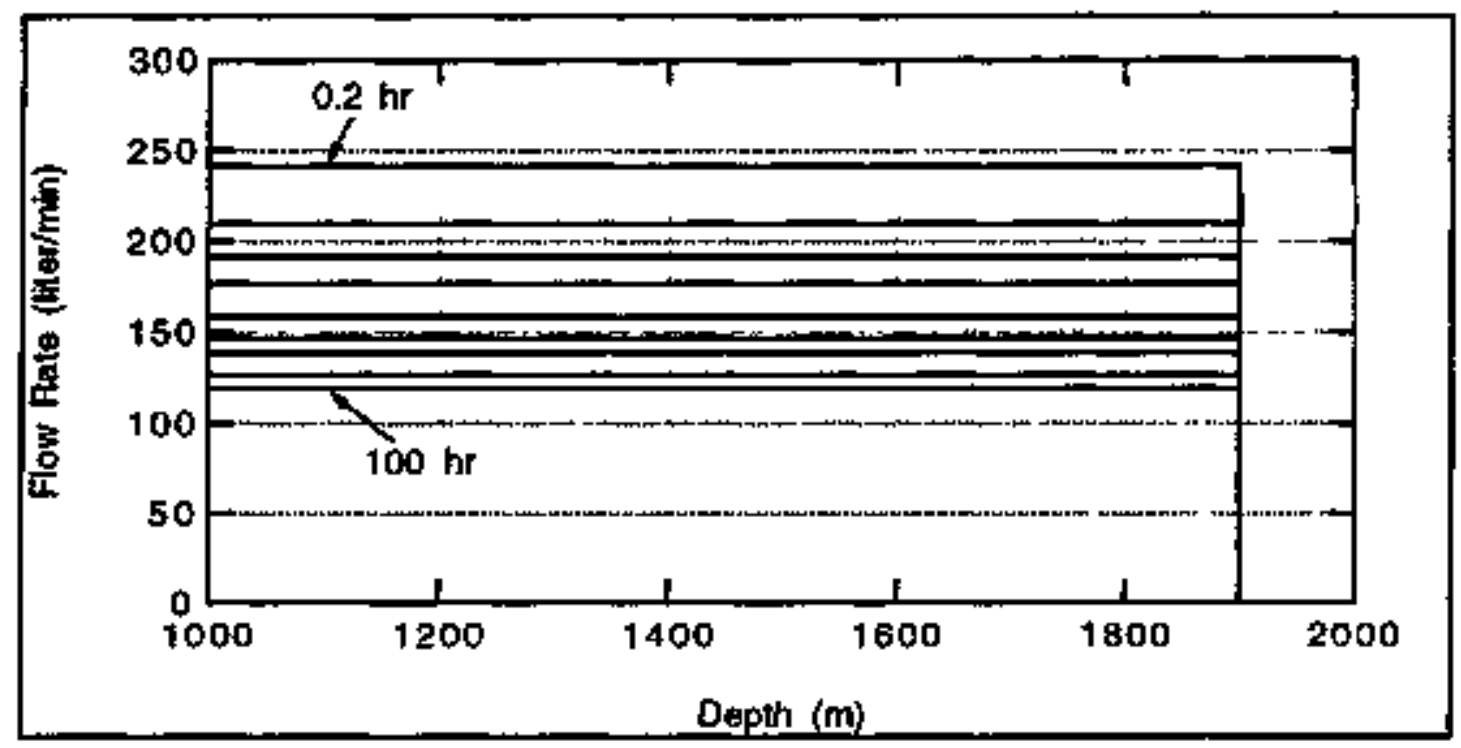

Figure 3. Flow rate profile for i-cell inflow.

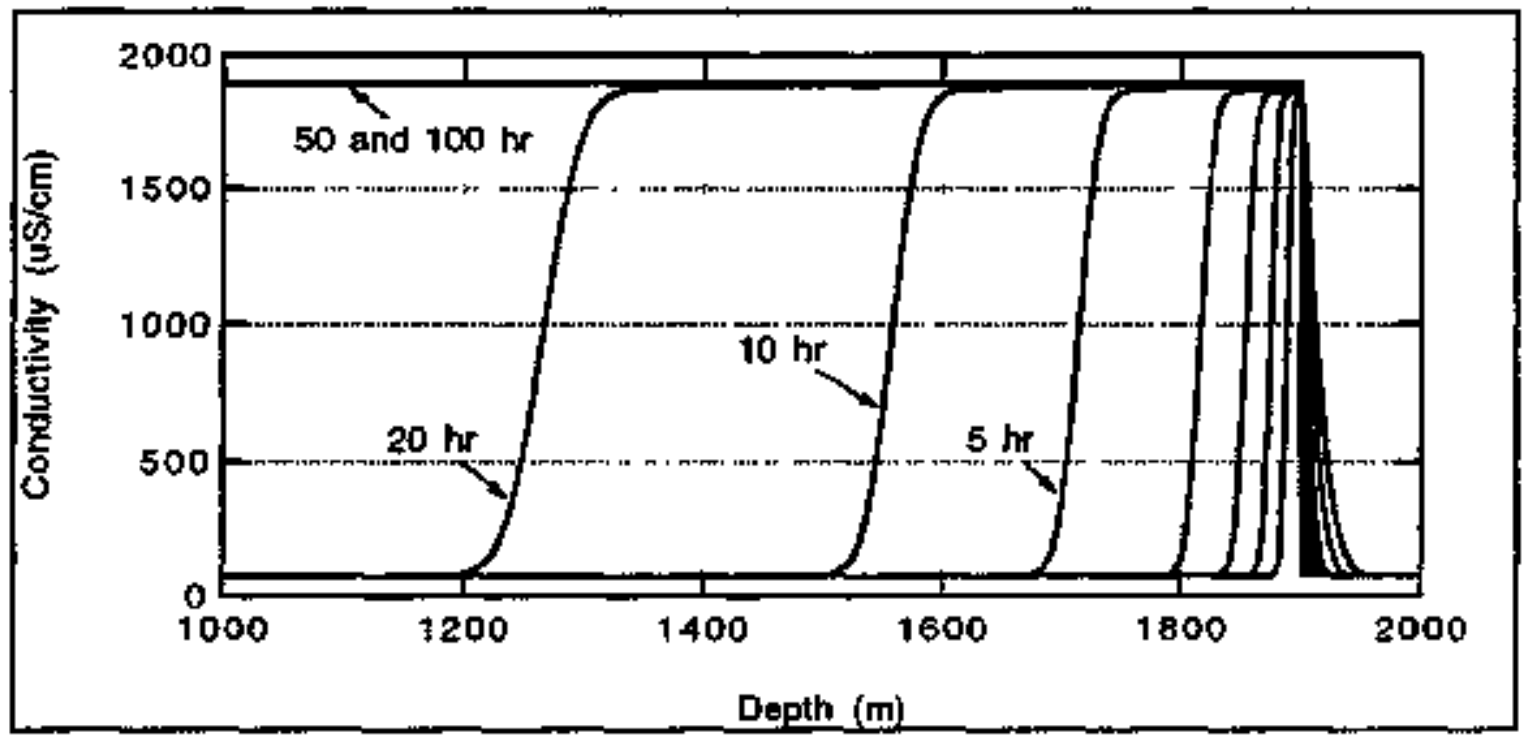

Figure 4. Conductlvity profile for t-cell inilow. 


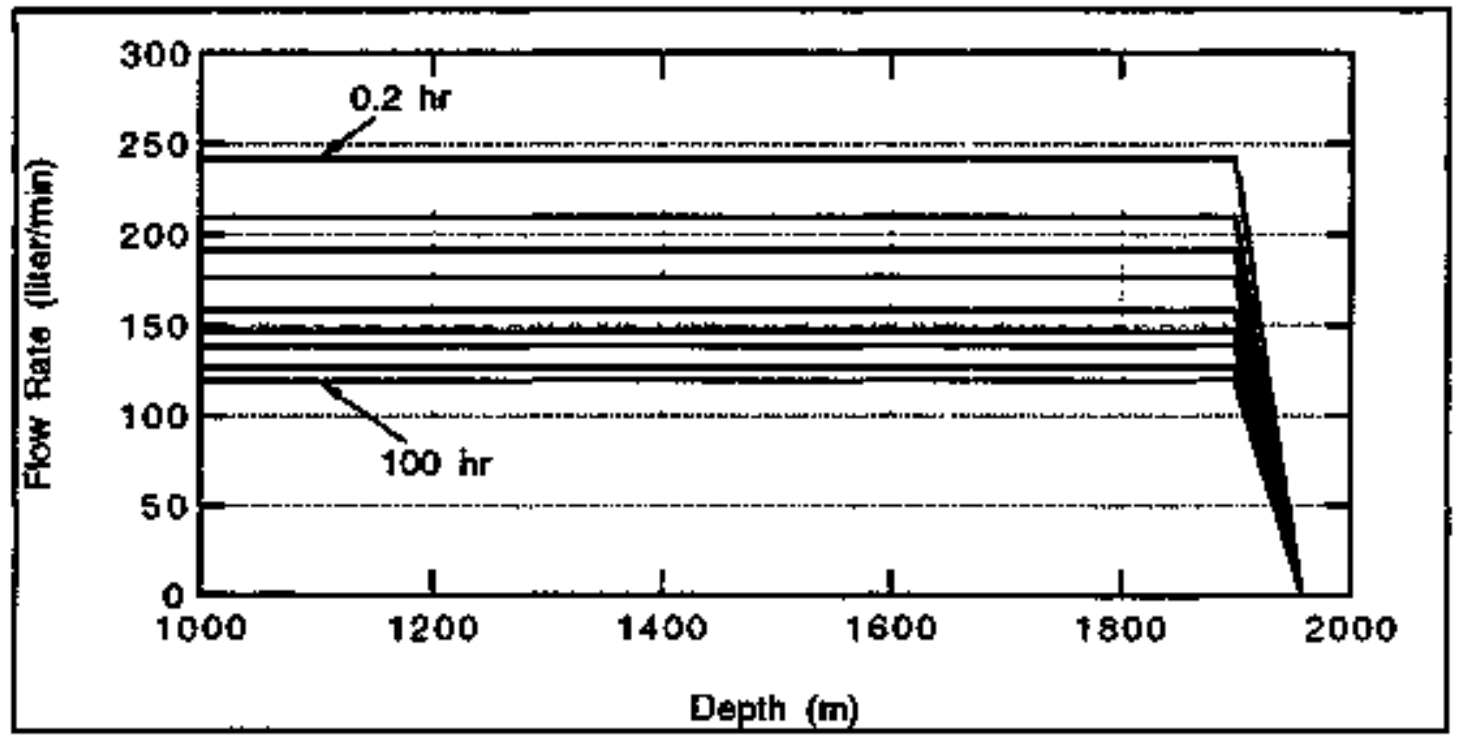

Figure 5. Flow rate profile for 58 -cell inflow.

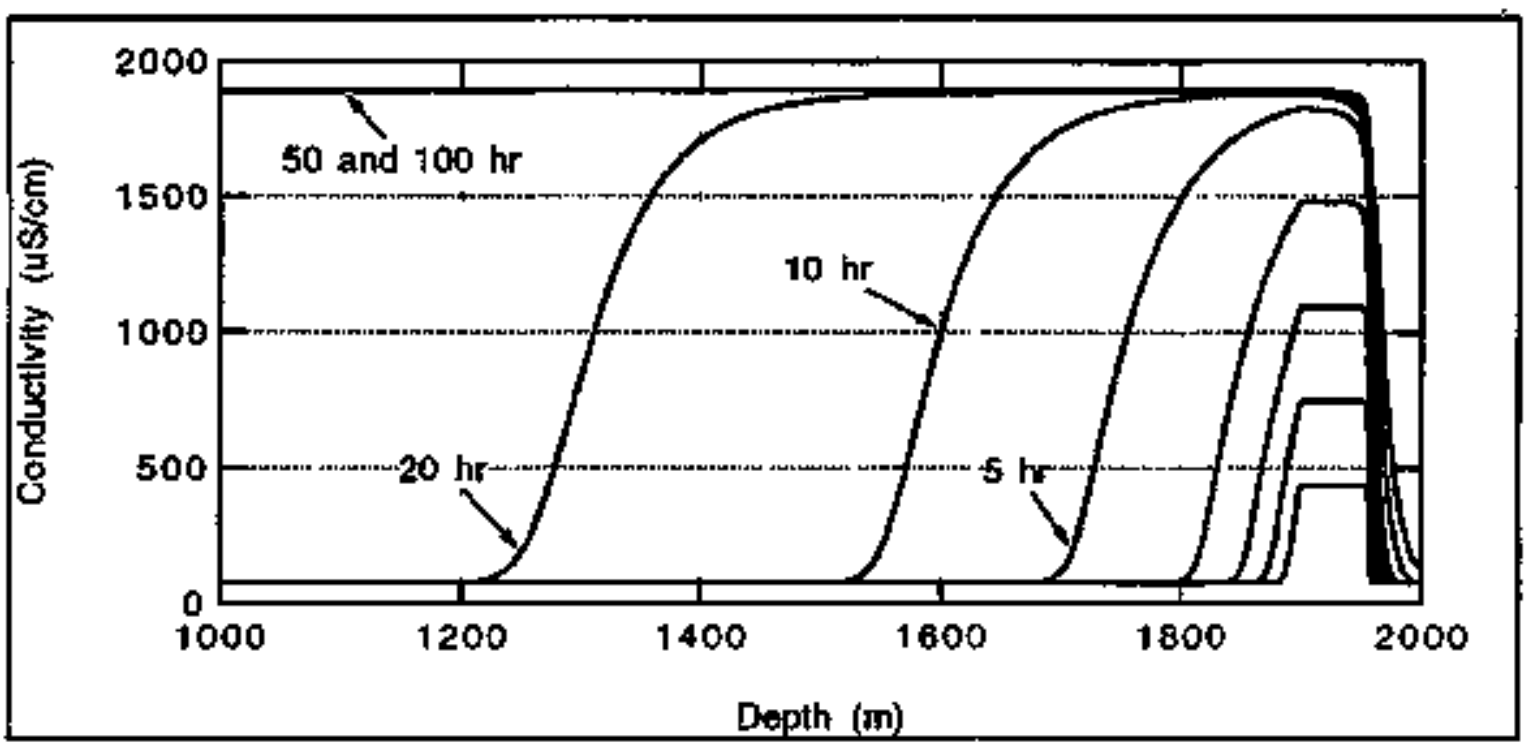

Figure 6. Conductivity profile for 58-cell inflow. 


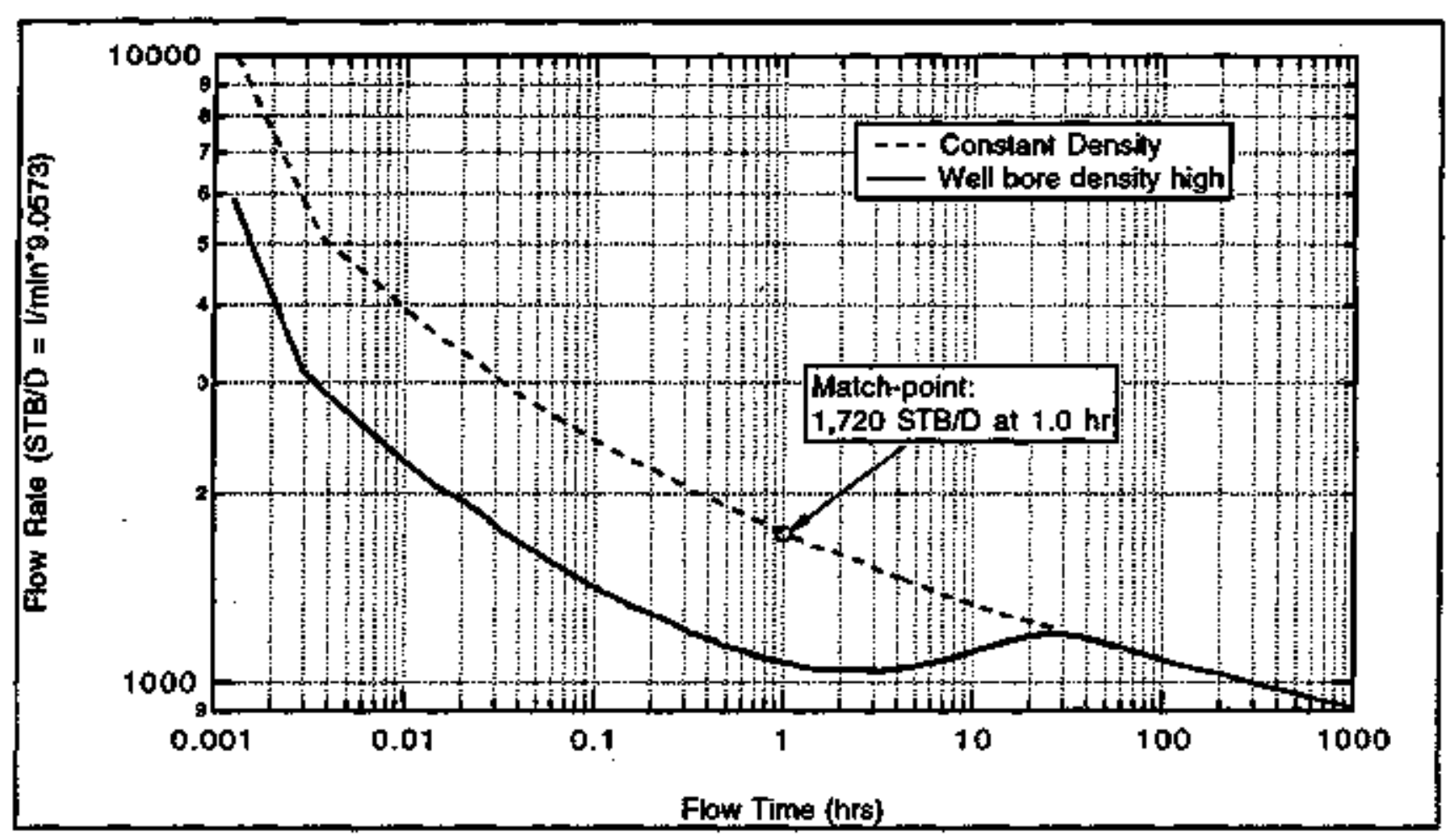

Figure 7. Flow rate as a function of time with initial well bore filuid density doubled. Initially, the fiow rate is lower than the constant density case; as the higher density wellbore fluid is flushed out, the flow rate converges with the constant density curve.

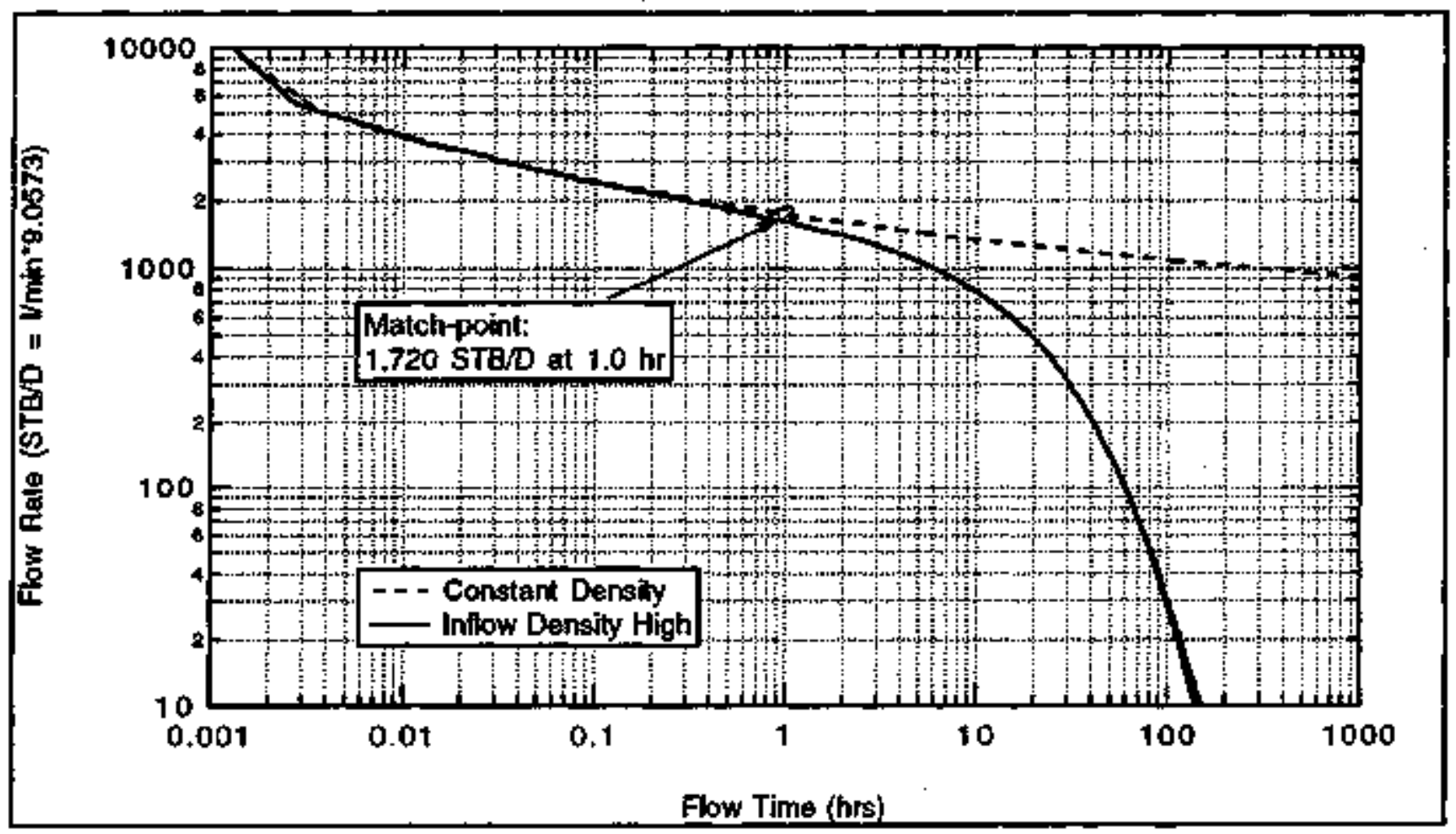

Figure 8. Flow rate as a function of time with inlaw density doubled. Initially, the flow rate is the same as the constant density case, but as the higher density fluid flows into the well bore, the driving pressure difference at the inflow depth decreases until the flow stops after a few hundred hours. 


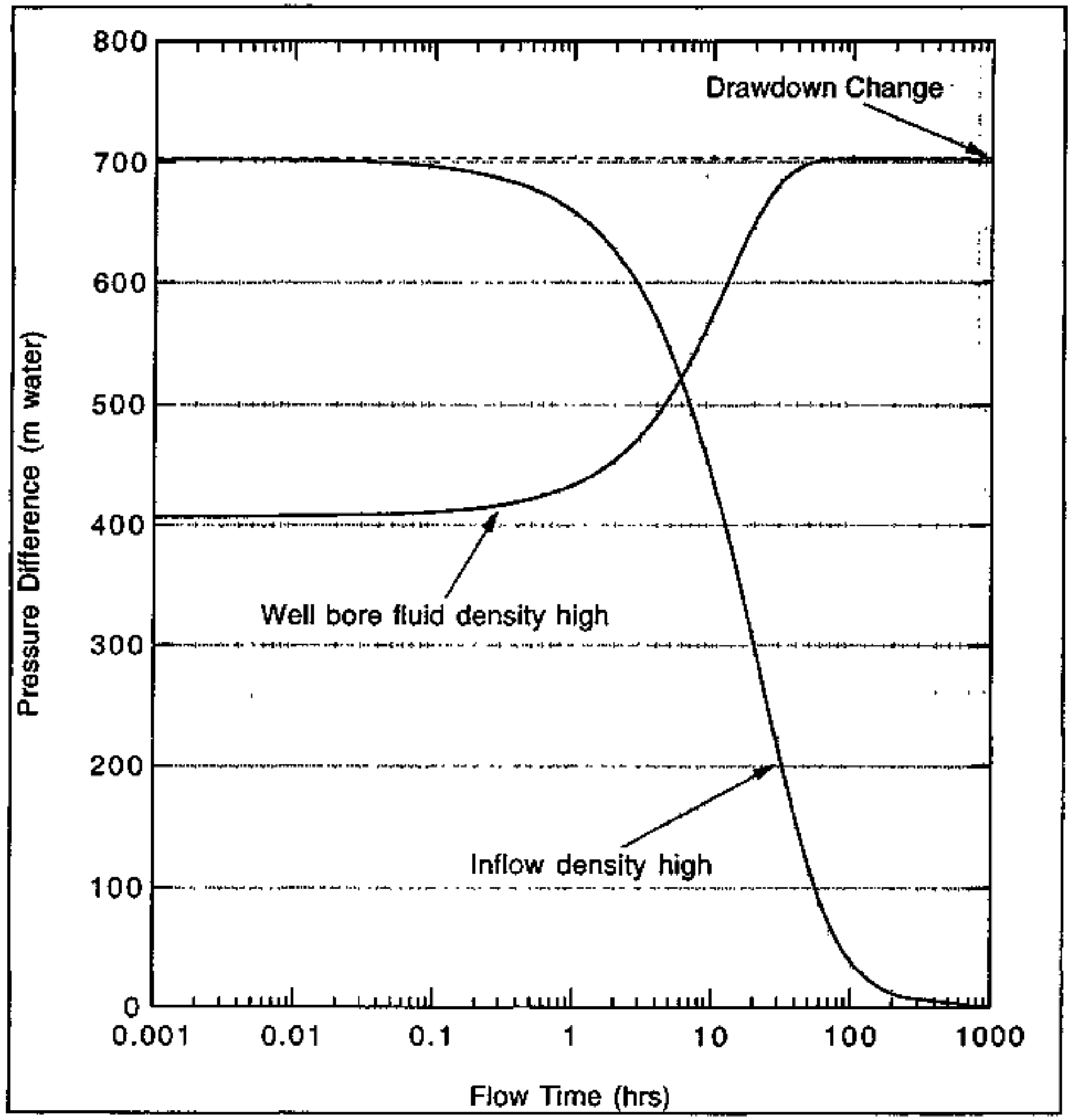

Figure 9. Driving pressure difference (in meters of water) as a funclion of time. For the constant density calculation, this is simply the drawdown change of 703.6 meters. With higher densily initial wellbore fluid, the pressue difference is reduced initiatly but converges with the constant density solution. With higher inflow density, the difference is initially the same as the constant density case, but decreases to zero as higher density fluid maves into the well bore. 


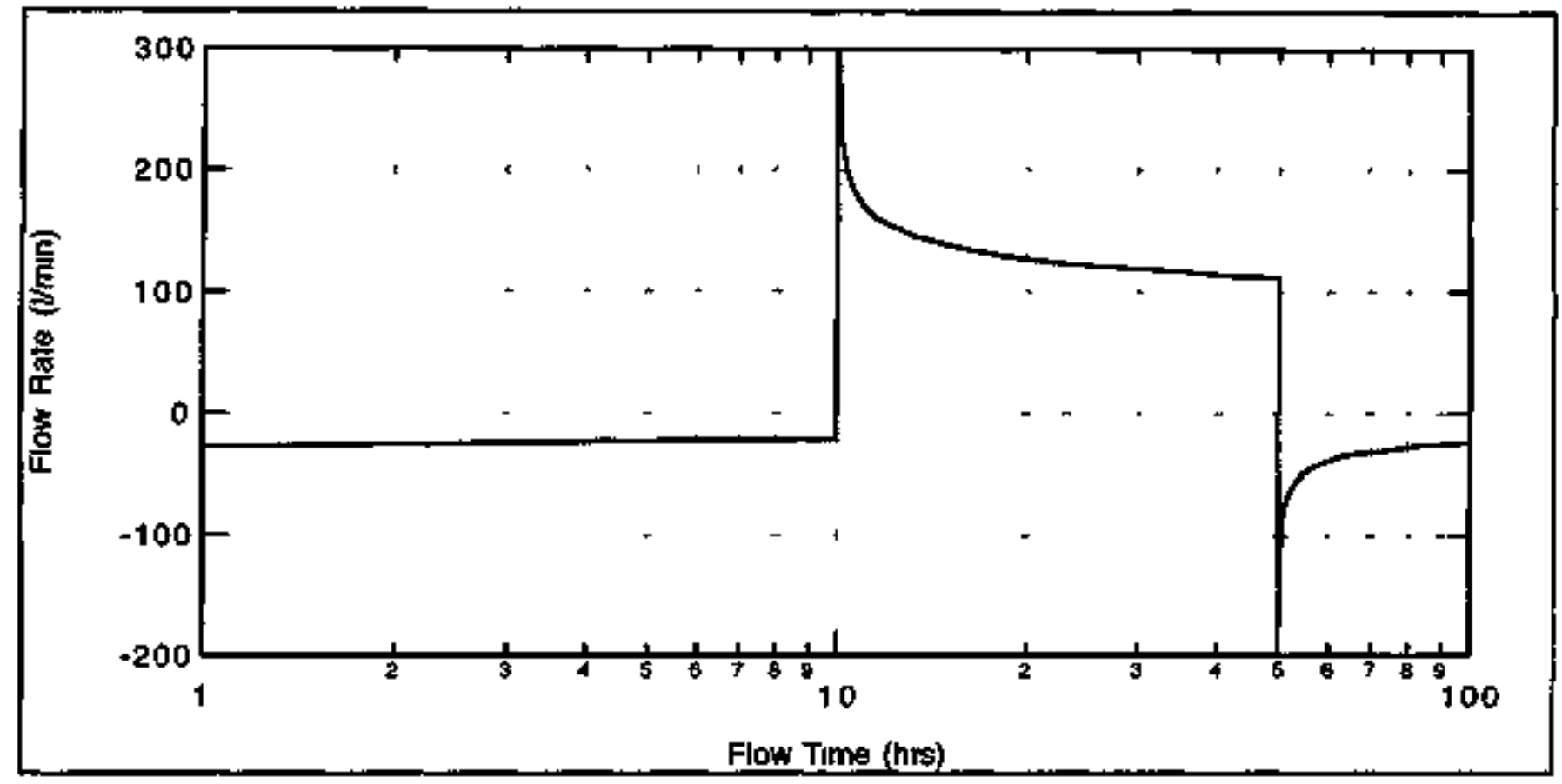

Figure 10. Flow rate as a function of time across the inflow at $1500 \mathrm{~m}$. Notice that the flow is initially negathe, from the borehole into the formation. The pump is turned on at 10 hours, and it is turned off at $\mathbf{5 0}$ hours.

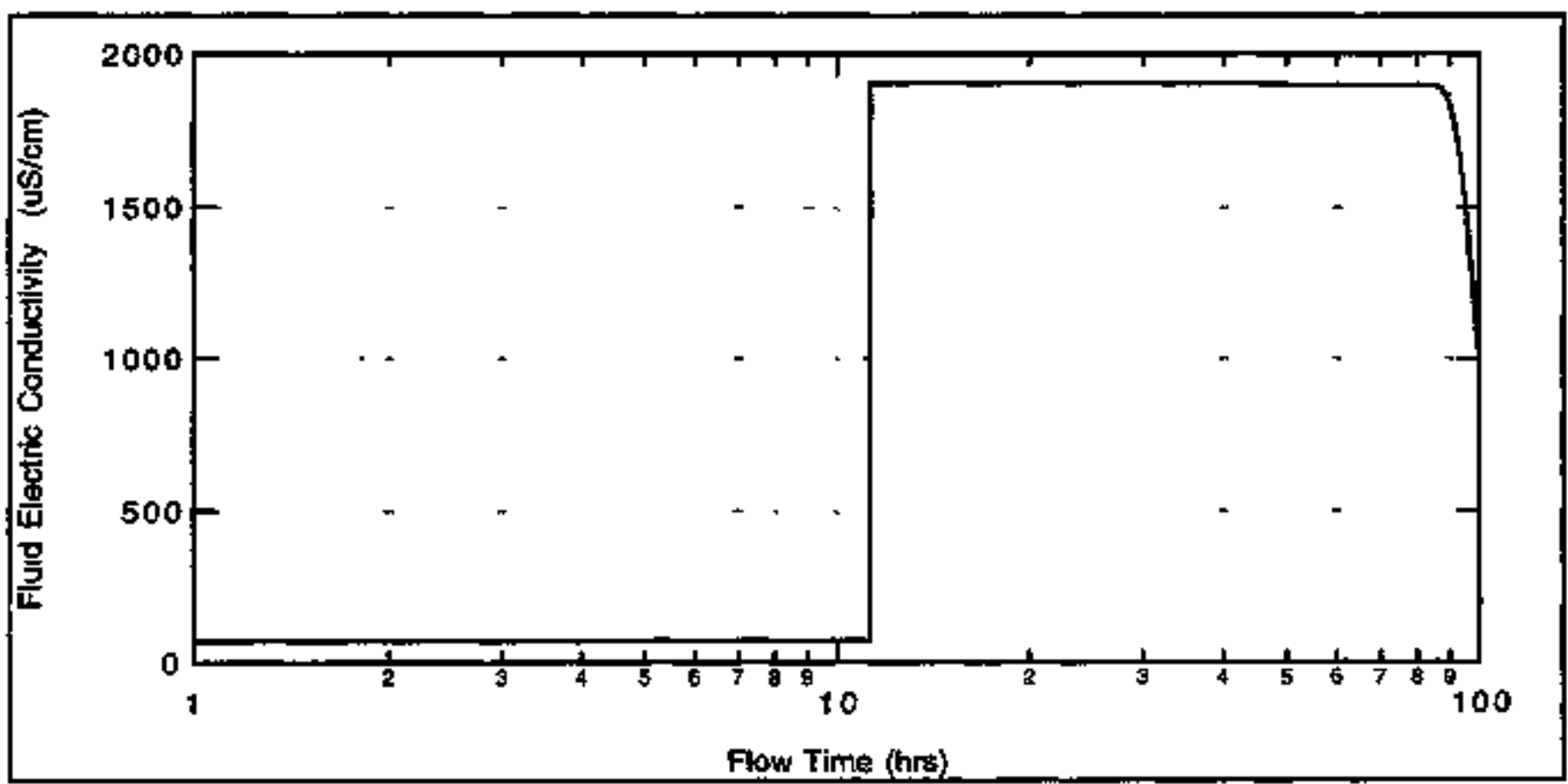

Figure 11. Fluid electric conductivity as a lunction of time across the inflow at $1500 \mathrm{~m}$. The most striking feature is the delayed rise in conductivity after the pump starts at 10 hours. This is due to pre-production infiltration of low conductivity fluid from borehole to inflow formation. At late tumes after pumping, as more of the high conductivity tluxd moves out of the wellbore, the concentration gradually drops as the front moves toward $1500 \mathrm{~m}$. 


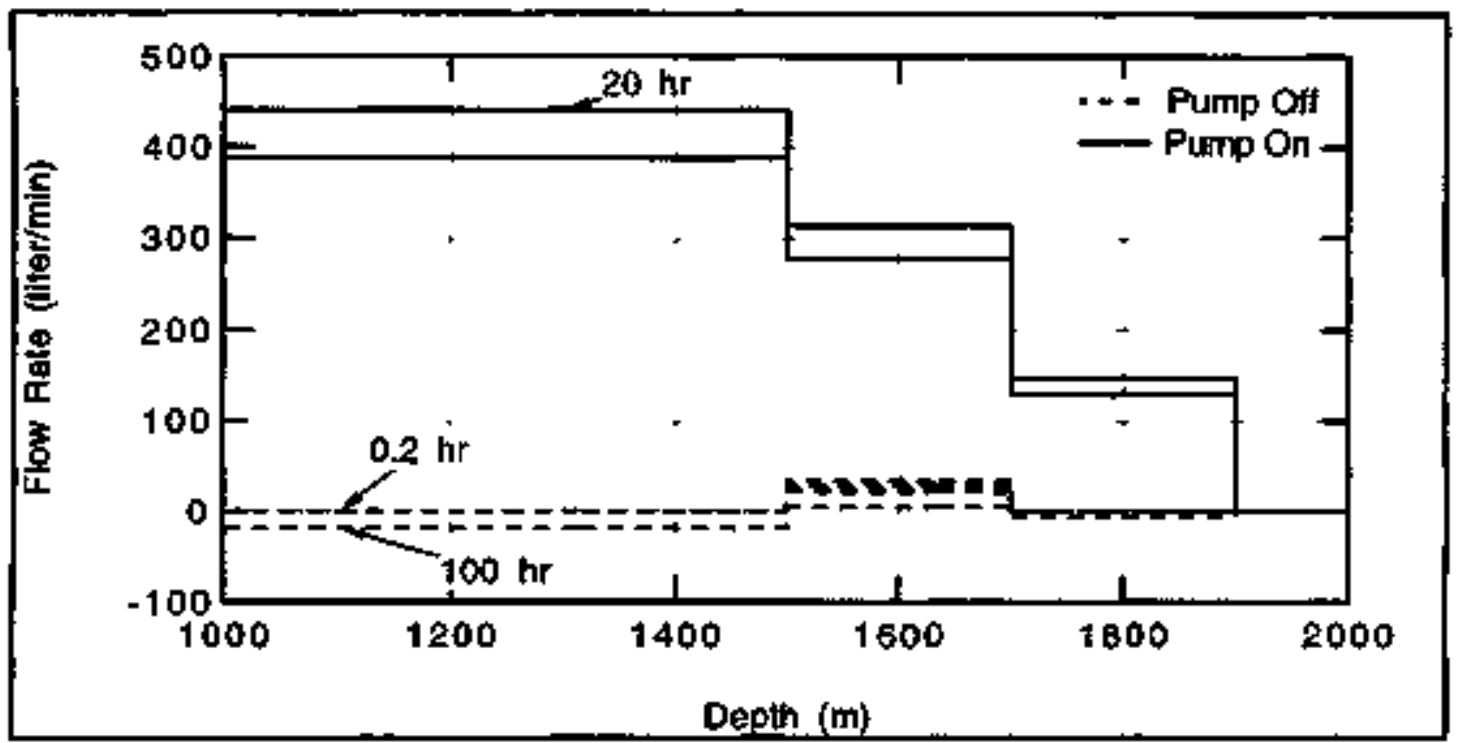

Figure 12. Flow rate profile for multiple inflow, multiple drawdown.

Before pumping (e.g., $0.2 \mathrm{hr}$ ) there is a clrculation from $1700 \mathrm{~m}$ to $1500 \mathrm{~m}$. Durng the pumping period (e.g., $20 \mathrm{hr}$ ), the typicat inflow pattern is seen. After pumping (e.g., $100 \mathrm{hr}$ ), there is a slight inflow at $1700 \mathrm{~m}$, a slighit outflow at $1900 \mathrm{~m}$, and an outflow at $1500 \mathrm{~m}$.

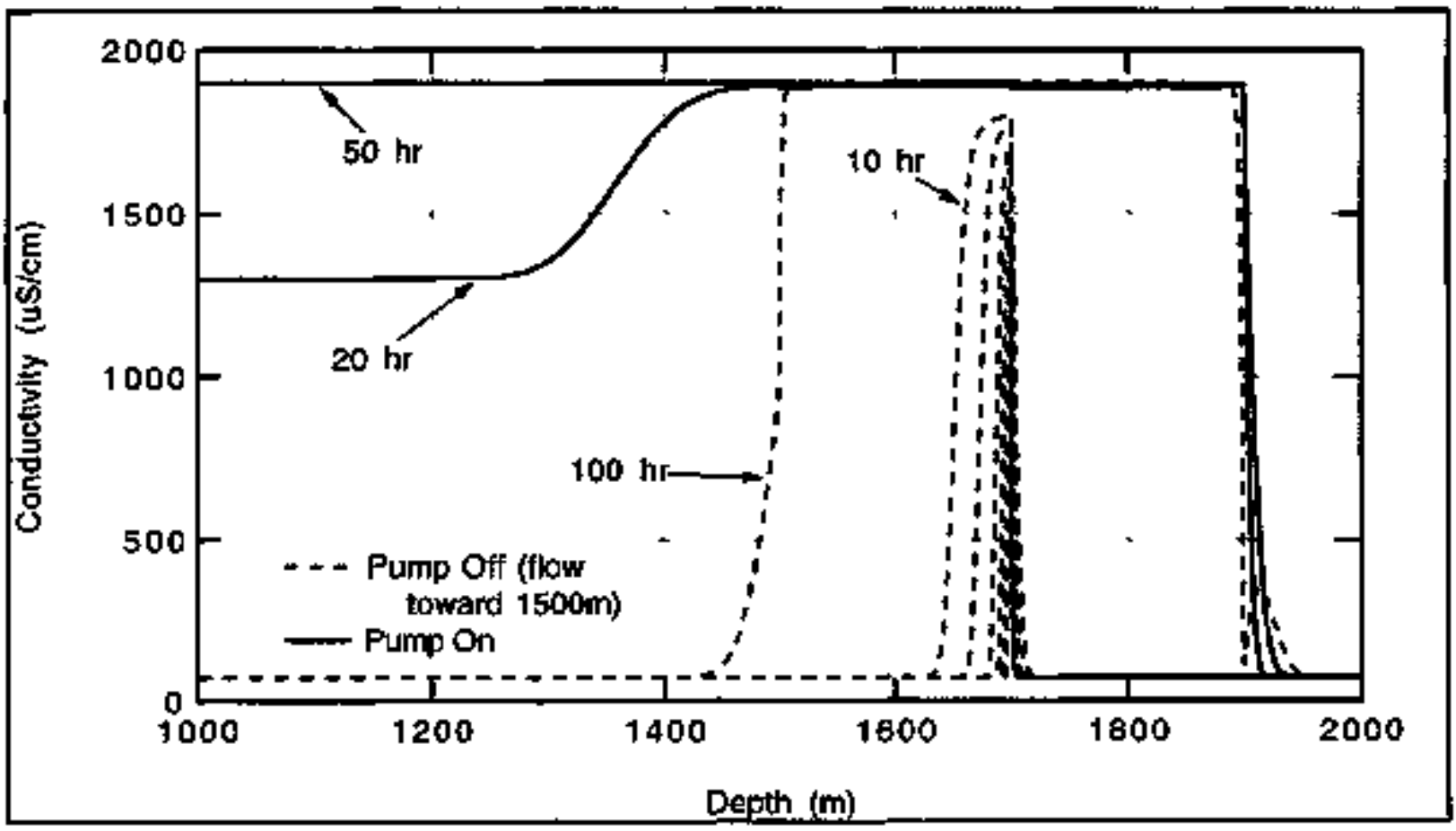

Figure 13. Conductivity proftle for multiple inflow, multiple drawdown.

Flow before pumping (up to $10 \mathrm{hr}$ ) is from $1700 \mathrm{~m}$ to $1500 \mathrm{~m}$. During pumping (10 to $50 \mathrm{hr}$ ), inflows are seen at $1900 \mathrm{~m}$. $1700 \mathrm{~m}$ and $1500 \mathrm{~m}$ After pumping (after $50 \mathrm{hr}$ ), flow is again toward $1500 \mathrm{~m}$, both from above and below, pulling the high conductivity fronts back toward $1500 \mathrm{~m}$. 
c*+. Erseture/borehole trankignt flow model

ct** lewromes berkeley laboratory, earth getenceg diviston

implicit double precision $[a-h]$
iaplicit doubla precision $[0-5]$

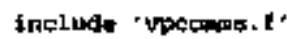

eall 1ntegil

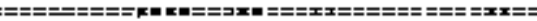

a BESINAING OP TIHE STEP LOOP

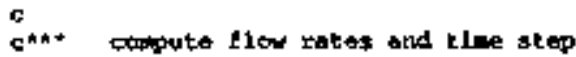

c 100 if Aivard.eng. 0) then

100 if tivard.equ

61:4

eall delows

endit

call onastip

fan If the time atog is to bly, try mogin

if (ifalle.og.0) goto 200

$$
\text { e.to }
$$

vrite $\{$ lout, + r reducing tina otep....

goto 100

c+r. tine steg niza la good

200 coll gowexton

if (t.le.tend) goto 100

$s$

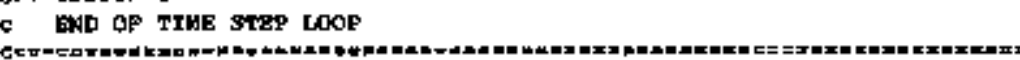

$$
\text { call entaprob }
$$

stop

contr gubrautirie flows

cat* calculake tlous through each begment

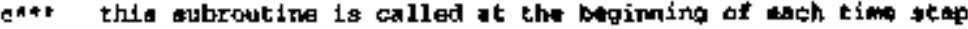
suburout ine clow日

implicht double precigion la-h impleit double procision $(0-2)$

[aclude 'vpecanne if

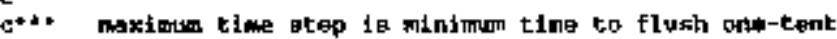

c*k. of a segant. noto that this tine may betill be too large

$\mathrm{G}^{\text {k* }}$ if disowrsion is signiticant

it ditalkte eq. o\} thon

de tatmax.no, a, then

delt $=0.3 *$ vol/gtmax

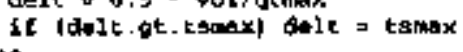

$\bullet$

ondif

cto fnitlalfzt segmunt t1ong

to lal. $\$ 1$ im

qEx̧aci11 $=0$.

qE

ckin ccabute flow into secponenta from fractures

chit it is possiblo to hat wote than ore fracture in a eingle

cto. segment

do 161, telte

cer compute flow rate as a funetion of pressure atoog

ainiti $=0$.

cats realculate effect of exoh presaure (arawdon) change

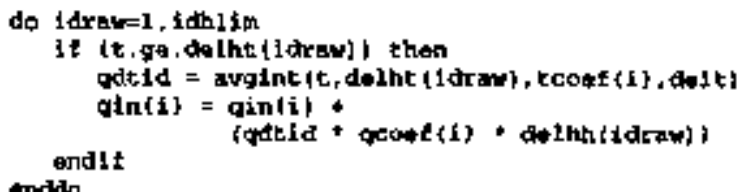

c.. calculate effect due to indtial conaition,

- nftracti $\}-\{x g$ (if

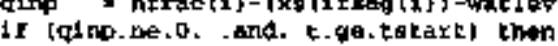
qdt id a agint $\{t$, tetart, tcoef $\{1\}$, delt $\mid$

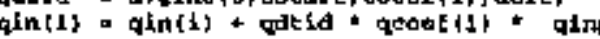
andit

$$
\text { call } 11
$$$$
\text { call rionsa }
$$$$
\text { return }
$$

subroutine oneatep (?

inplieit double prectolon is-h; imolicit double precialon $(0-z]$

Inaluate 'vocomes . $f$ '

1falle * o

$\begin{array}{ll}\text { to } & =\mathrm{t} \\ \mathrm{t} & =\mathrm{t}+\mathrm{del} t\end{array}$

cal. gave current mas and volume totals

gtolns = gtaninn

atdire : Atdina

gtens * gtmout

otale = otdout

gtthine - ot the

stbfma - itberal 
gtvins = gtvise

gtrot - gtvout

otficm = attbu

gtbeva - otbt

towas $=$ topm

$c$

c.. compute fracture infloms and concentrations to the borehole

enll etrrac

c** compute was crarbfer for the elme atep

$c$ mil tatom

returs

end

čn complate a clan gtep

c घubroutine goodakapi]

c ingleit abuble preciaion (a-h) Impilalt double prectsion $(0-\mathrm{z}$

c

药 include 'vocomons, $f$ '

\section{to $y=1, \pm 1 p t$}

if (t. ge.ptif) thon

$$
\text { calt pret }
$$

$$
\text { endelo }
$$

if Idelt. le, 0, ther

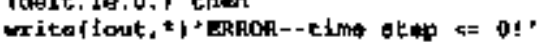
atop

亡

teavg = teavg a Aol

ntetep * ntetep +

lf (dadt.lt. talo tolo $=\operatorname{tat} 1$

It idelt.gr.tshi) tohi $>$ delt

got. prite extra output tor report plot:

$c \quad$ efr $=$ etractifsagil 1,1 ,

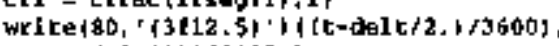
- tainit)*60000.) rekurs

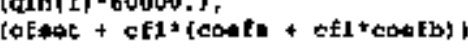
ond

c*+n lintialize conatants, otc.

$c$ mubroutine intes ()

c inolicit toubl- brteision $(a-b)$ iaglefe touble preciston $(0-2)$

c Include 'vpermong 1 '

$\mathrm{C}^{\text {nth }}$ Input and infeiplization

$c$ do $\{=1$, d mx

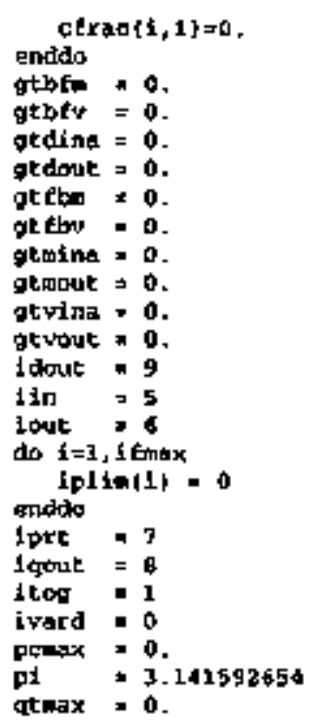

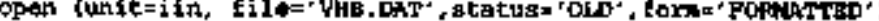

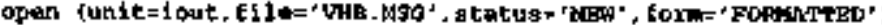

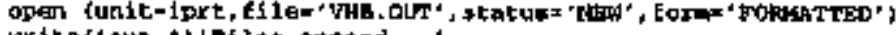

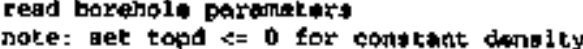

xtop ds top of analyais rotion $(\mathrm{m}\}$

xtop nay be adjuttod during disoretization

xhot to battow of andyulit rogion im

mate: $x$ increaseg downard, terd at jurfacs

delx la angment longth in th

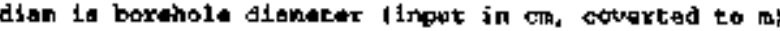

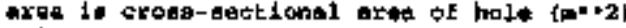

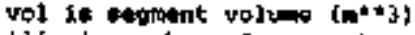

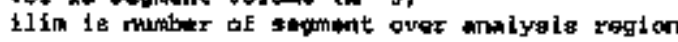

cutk Inpot stread--one free cortrat recond

c"th xeकp, thot, delx, dism

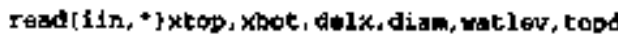

if Itopd,gt.0.1 then

ivard $=1$

0140

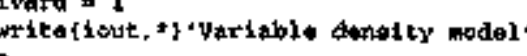

topd $=1.0$ and $f$

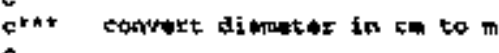

diam = diam $f 100$.

ctht chack goconery

1f (xbot.1t.xtop) then 
Fibore.t

\section{Wad oet $516,04+321994$}

veita(10ut, 940)

9top

andiat $=$ xlotet-xtop

$x$ int $=x d y=x /$ arix

vitip(10uk, 950)

stop

endit

ilin in $x$ int

If 111 im.gt.imaxi than

orito $\{10 u t, 490\}$ inss

stop

andif

$x$ top $=x t o p$

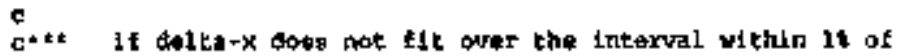

c*t* ateles-x, ther make a note

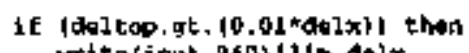

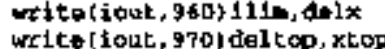

w eles

andit

c.+..

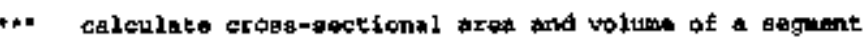

rad : d1am/2.

aren - Did traditad

er.s cerreato mogment 11 topines

ctst noto-tion roversed tor oraphing

do $\mathrm{i}=1,11 \mathrm{~m}$

$x s[1]=x b a t+(0.5+1)+d e l x$

cout read thos trom trackures

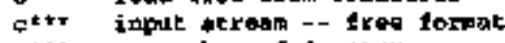

c... Tnenter of tractures

at+. one record for wach tracture

c... Dosition $(m]$, flow ratk $\left[\boldsymbol{m}^{* *}+3 / \mathrm{sec}\right)$. Concentration of

$c^{n * \hbar}$

c

c... rend tracture tisted

\section{roodition *Ylflio}

If (At)in gt. ifmax' then

ritat(10ut, 910) itmax

endic

endic

do $i=1, j$

If (ivard. of them them

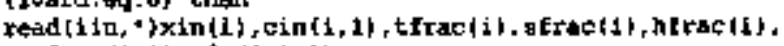
vitacil, $11,+f_{2}\{t, 1,1]$ $\operatorname{cin}\{1,21=1$.

$+100$
3

rood $\{$ in, $* \mid x i n\{1\}, \operatorname{cin}\{k, 1\}, t$ frac $\{1\}$, afrac $\{1\}, \operatorname{Merac}(1)$, ardit:

vfrac $\{i, 1\}, \operatorname{cfz}\{\{, 1,1\}, \operatorname{cin} \mid 1,3\}, 0 \in z\{i, 1,2\}$

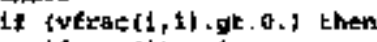

1) zman $(1)=1$

elso

endif

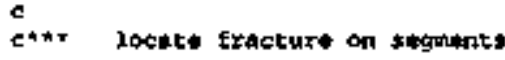

lekipit $=0$

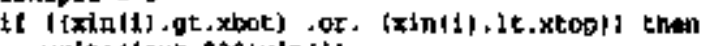

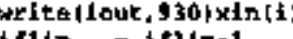
itism $=1211 \mathrm{~m}-1$

$$
\text { iskitio }
$$

if \{taloloit, or thon

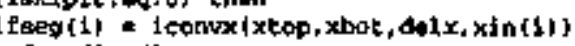
rad o diam/2

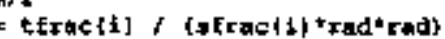
andif

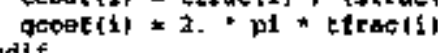

midido

ctes resd dranciomn and times

et*t loput akream -- Eres forplat

rupaber of changas

$e^{* * *}$ one record tor ateh change-

time throl, drawdown [im]

c.t. read drawdon dace

rotriin "rlethlsm

if tiathl im, gt. Fithonats them

writediouk, 1910) idheax

atoo

c j=idhl trm

c do ine,

readifin, - ydel ht i i , delhh (i)

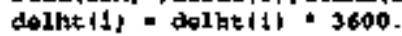

'enceata

c... read $t$ ina paraneters

c*a. input stroan--

c*k* sente cino (hr*), end tint thrs), rumber of printe

otht then, print times ihral

cente

resdtilin, *1 tetert, kend, tanax, ilpt

tetart = totart 3600.

tend tend:3600.

e

14 (teand It totare) then vrite thout, 2920) orop

it (lipt.gt.1net) then

write (fiont, 915) 1upt

andif 
c+4* read in gridt-time paramoters

c

$$
\text { Twad \{11n, * \{ \{pt } 11\}, 1=1,11 \mathrm{pt}\}
$$

do te1, ilpt

pt $(1) * p t \mid 11+3600$

$$
\text { enddo }
$$

c... read dippersion paxamater

ca.: inuut strean--fond record

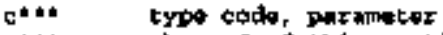

c*nt at the end of thla routine, dke has witte $m^{4}+3 / 8 e c$

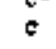

roadidith, rikgrdk, ask

c*t. lf ityodkn, value is conttant over tll kerments

cut if itypdir=2, valur is far math velooity

ctht If itygdema, value is tor mean velocity sovared

$$
\text { dxal = dk* araz/delx }
$$

do $\mathrm{i}=2, \mathrm{ilim}$

enddo

c... read inteisi concentraklong and deneities

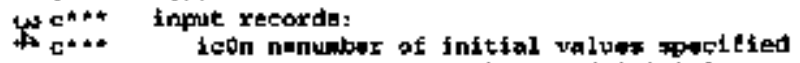

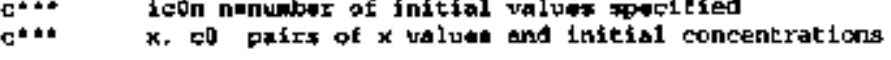

c

$$
\begin{aligned}
& \text { do } 1=1,1\} 1, \\
& \text { ckt }\{1,1,21=0 . \\
& \text { ext }(1,1,2 \mid=1 .
\end{aligned}
$$

endio

$\operatorname{ext}(1,2, z)=1$.

$c$

readilin, *ilcon

if ileton, ge. or then

do $i=1, i \operatorname{con}$

It tivakd ac a then rositin.

elee

reandilin, $* \mid x, c_{0}$, d0

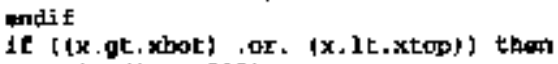

$\rightarrow 2$ wetricont, 900 ix

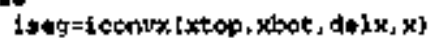

if faxk (iseg, $1,11,6 \mathrm{~d}, 0.1$ then

ext $\{1$ Beg, 1,1$\}-c 0$

ext $(1 \mathrm{geg}, 1,2\}=d 0$

else

triteriout, 3910)*$$
\text { eradic }
$$$$
\text { endit }
$$

entifif

int oftet to the baekground conductivity in $\theta / m$

c*.. coefa to tho inmenr torr for convinting concentrations

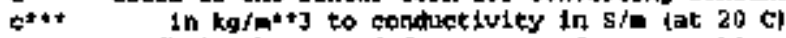

c+rt coafb is the second degreg term for convathing

concentrations to ondusctivity lat $20 \mathrm{Cr}$ c

c

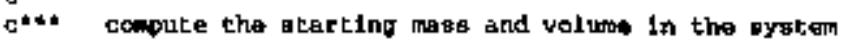

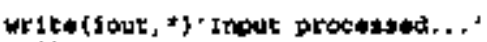

tail

toED $=\sin$

tdto = iat

ton $=20$

$t \rightarrow E 0 \quad: \quad s=6$

two $=$ pvi

vatlewo $=$ vatlov

toropl : (xtopuratlev)*are

tormo intilim, 1, 1) t top

topst = topd

tohi $=0$.

tolo $=1 . e 30$

toavg $=0$.

nterepe $=0$

dolt $\quad$ to.001*tanax

topy $=$ topurl

ratum

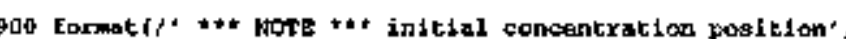

. Imalka-cignored

$$
1 \text { Mosition it ', } 115.51
$$

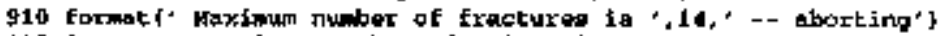

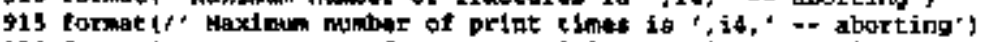

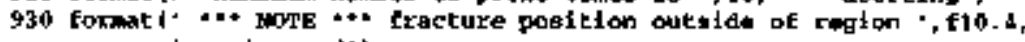

9do tombel. Top of retion is below botton of zeglon--eborting'?

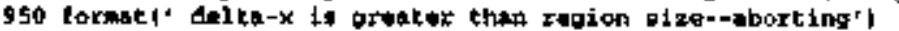

960 tormat 1" Region has been dividad linto ', it," gegments with',

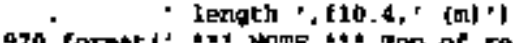

970 forneti in NoTe "." Too of region has been waved by ',

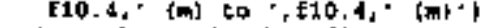

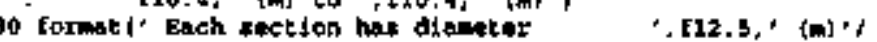

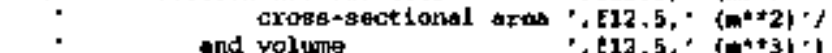

990 toregkl. Maxim number of

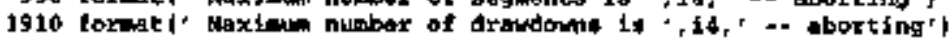

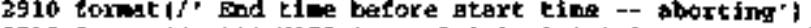

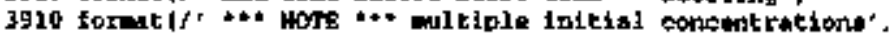

' for one segment '

and

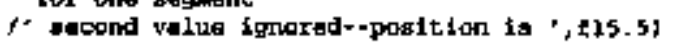

ch+h tunction 1corivx

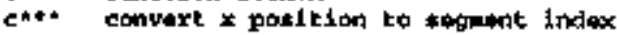

e** styment 1 beyins at xbot

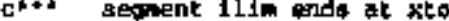

ctet this function ig used outlade of time atops 
imoliett doubl procktion [o-z]

1dxup $-(x$ thet -x) $/$ del $x+1$.

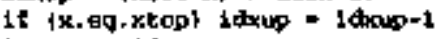

1 conve = 1dixue

returt

cton cospute the magd and volune in tha gystram

subrgot dina mass (1)

c a forlicit touble precteion $|\mathrm{a}-\mathrm{h}|$

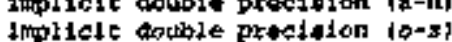
include 'wocones. 6 ' Int $=0$.

cter sum mage in borkhol.

c do ixl, 11in

anb - 2nb + ext $\{1$, t togr, 1$\}$

$$
\text { ardido }
$$$$
\text { Bint = amb }+ \text { yol }
$$

ctit cospuca volune in borehole

c swb + ilin + vol

c... sum mass and wolum in fractures

c $\operatorname{gof}=0$

$\rightarrow$ I $=0$.

SQV $=0$

do III I IEITH

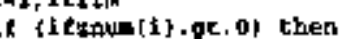

to $j=1,1$ amonil 1 .

Vbj - vEracti,j

$\operatorname{sen}=\tan f+c t z(z, j, 1) * v h$

sdf $=$ adf $+c E z\{1,1,2\}+v i$

ave $=\mathrm{avf}$. vij

endit

return

$c$

Ga.. Eubrout 1 ino eprt

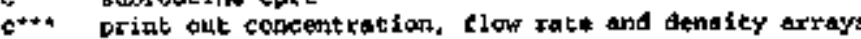

cth. thil subcoutine is executad whenever concontration arroys

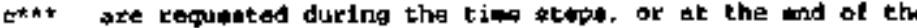

ct. problem

cor note: units of gukput corkhuctivity is $\mathrm{s} / \mathrm{m}$

aubroukine cprt

inollolt desble precision th-h)

implict double precistion touz include ' Ypoomeng , $\mathbf{T}$ '

ct+k outbut kima in hours and concentratione with afcurding

fat* valuet (note mogative inoremerte in lioopl

c... output tike in boura (corrvert from seconula)

$\mathrm{th}=\mathrm{t} / 3800$.

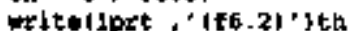

wrike $190 \mathrm{cot}, 186.21$, th

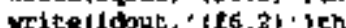

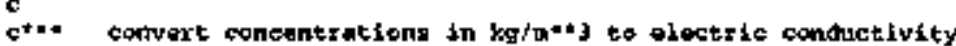

gta in us $/ \mathrm{cm}$ uelng input coeftictents

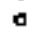

$$
\begin{aligned}
& \text { do tel,ilim }
\end{aligned}
$$

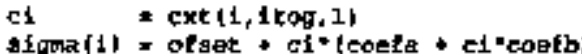

$$
\begin{aligned}
& \text { qIm(i) } \quad 50000 .{ }^{*} \text { (In) }(5)
\end{aligned}
$$

writatiant, 920$\}$ th

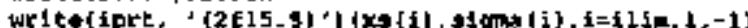

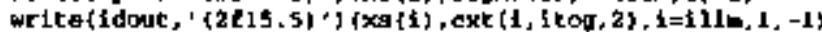

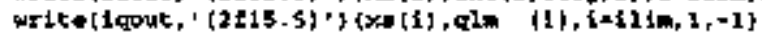

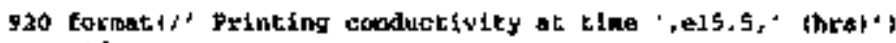

at. end of problem

subroutine indprob?

inolicit deubla prectiolon [a-hb fiolicit Aoubla precilaton $(0-2)$

include 'vpsaming 1 '

c.'. chock for tinal print

needp $=0$

do $\mathrm{j}=1, \mathrm{ilpt}$

1E [Dtif] .1t. 12.*tendil needpel

if ineedp.ne. oj cait cprt

cta. ead of problatin, chwek mang conopruation

eail knass

c... total system mags

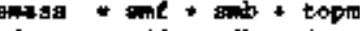

edeng $=$ gde + sith + (kopdktopv

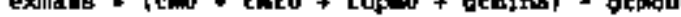

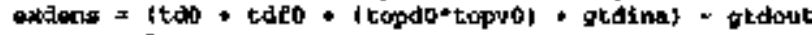

pert $x 0$.

dert $=0$

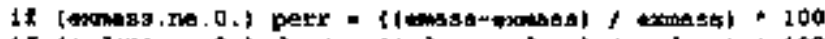

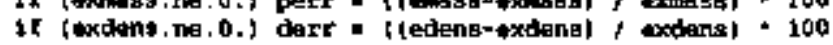

ge.. eracture mats 


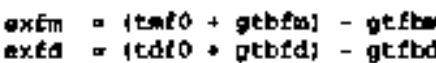

plert $=0$.

dfarr $=0$.

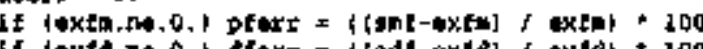

c... tokal systam volume iconvert Erom $m^{* 23}$ to 11

it (topro.qk, topow then

gtwout $=$ gtwout + itopvo-topvi

由l一:

if Itopvo.1t.topvi gtrina = gtvina - (topy - topvo|

indif

avt - But 1020 .

sit $=$ sut $=1000$.

topu $=$ tops +1000 .

cvo = tvo $* 1000$.

trta = tvto $* 1000$.

topro = topwo - 1000 .

gtvint = otvins * 1000.

gtvout = atvout * 1000.

gthfy = gtbfv * 1000.

gtelpr $=g t \mathrm{tbu}+1000$.

$\omega^{\circ}$

arol a svt + twb + top

exvol 4 (two + tyto + topwo + gtvinal - gtwouk

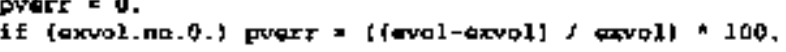

c**. frackure voluwe

extv - \{kto + grbtv - atfbv

pfverx : 0

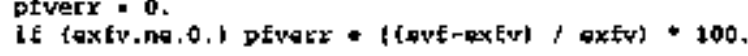

write (lost, " $"$

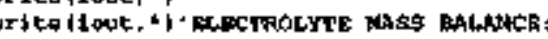

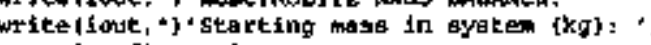

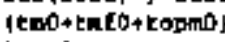

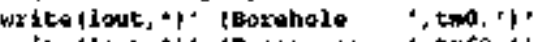

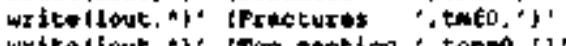

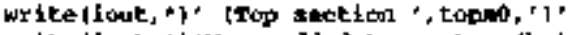

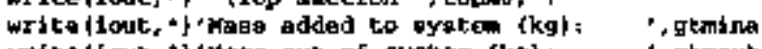

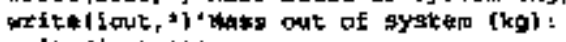

ariteridout, *

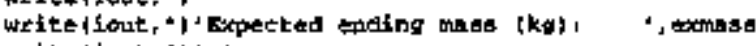

writeilout, " i Actual ending misss $(\mathrm{kgl}$ :

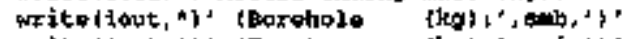

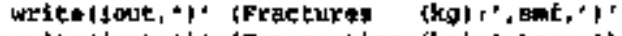

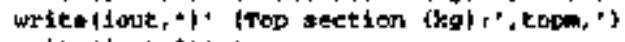

write (imat. nj C Mercent arror

Dowr

c

writellout. "

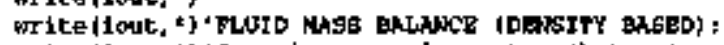

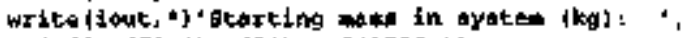

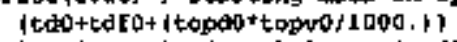

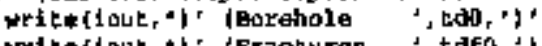

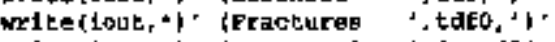

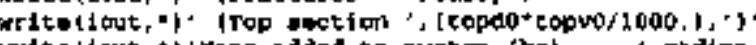

miteilout, * i kase added to system (kol; ". ptdina

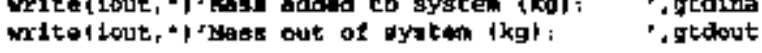

write tiout. +1 .

wrike (hout, $*$ ' Expected ending mags (kg), ', axdong

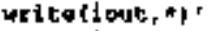

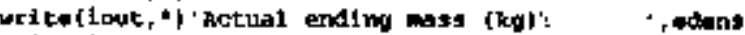

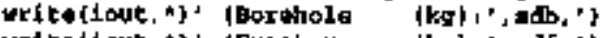

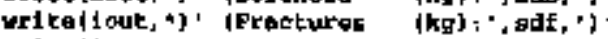

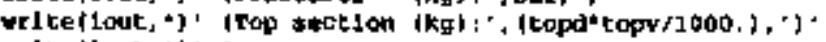

mike[lout, " $)$ "

writelilout, +jeparcent orror

vritellout, ").

miteriout." "WOUANB BALANCE:

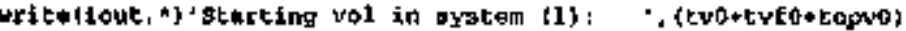

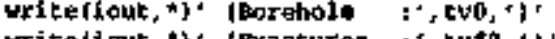

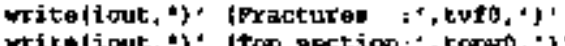

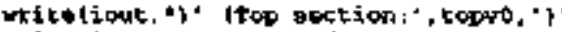

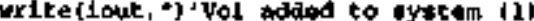

write(10ut, nival ort of sysketh (1)

mrike[1 put, *

writeidouc, " ' Bupected onding vol 111 ;

+gtvisa
iglvout

vriteriout, $*$,

writeflaut, " Actual anding vol $\{1\}$

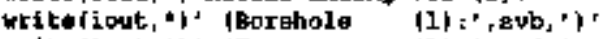

exvol

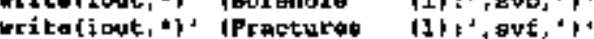

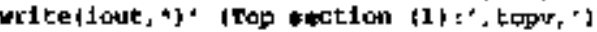

writelilout, $\left.{ }^{2}\right)$.

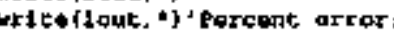

mite (lour, "\}" ?

vriteliout, $*$ ).

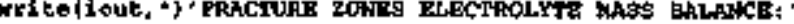

writeilout, ") 'starting hass in frac (kg) ! ', tento

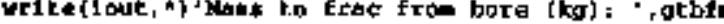

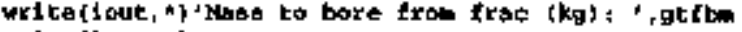

urlteiliout, $"$ )

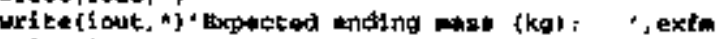

vititeliout, ${ }^{n}$ )

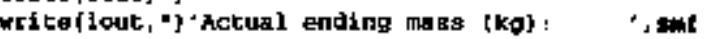

writorlout. " $)^{2}$

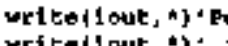

oferr

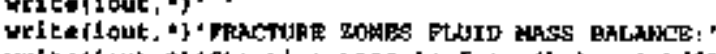

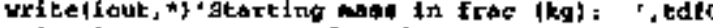

mriteliout, "Mass to frac eron bot $1 \mathrm{kgl}$ : "gthed

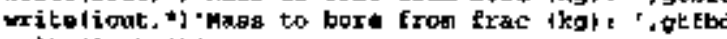

vititeliaut, * $*$.

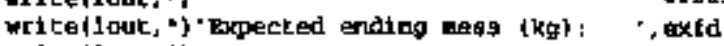

writediout, ")

miteiliout." "hatual ending mess (kg): "ath

mritellouk, ${ }^{n}$ ?

writedlouk, $k$ 'percent error:

miteliout, $*$, ?

Mritellouk, ty'TRACTIRE gCANES VOLARE BALANCE:"

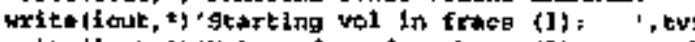

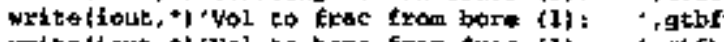

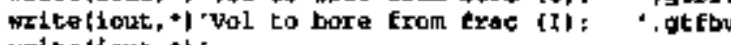

writetiout, +1

write\{1out, " Expecoced ending vol \{1\}: "Axfv

write\{fout, $"$ "

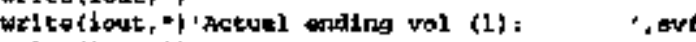

Write (kout, $* 1$.

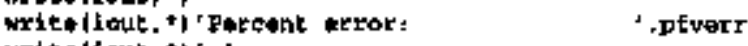

NTite (foute, + I

Nritelicurt,

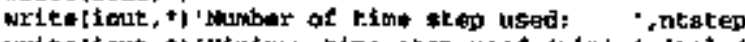

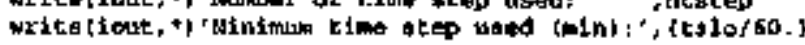




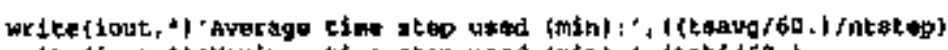

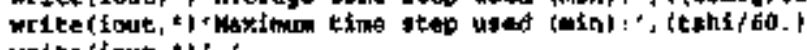
writoisout, $n$,

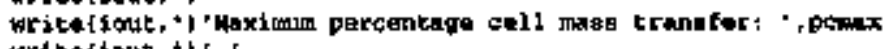
writeisuti,

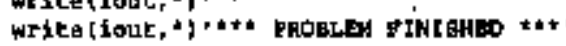

return

(a) and

crot. unbroutine tatep

c.". calculate cencentrettong at next tim atwo

zoutine

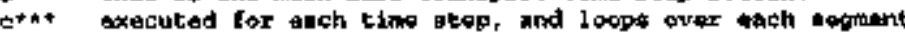

c subroutine titop

impllalt double prectgion $|\mathrm{arh}|$

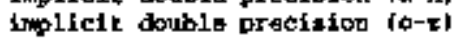

e

include ' vpeomus $\cdot \boldsymbol{t}^{+}$

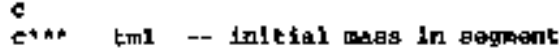

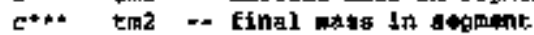

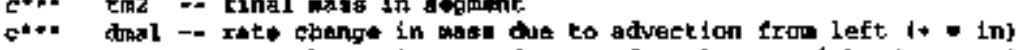

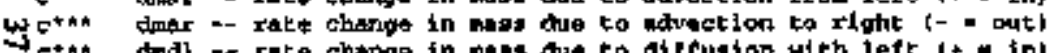

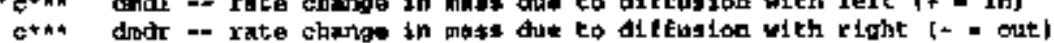

c".. dinf $7=$ rate chang" in mess the to tracture inflow it a int

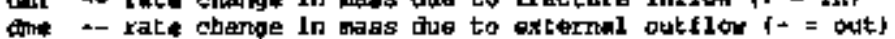

tocemara top only

pept $* 0$.

fact $=1.930$

inne $x$.

c

ci. low gywe wach togment

1togx *3-1tog

to $1=1,111 \mathrm{~m}$

$i_{i=1} \times 1+1$

$\operatorname{ext} 1=\operatorname{ext}|1 \cdot 1 \operatorname{tog} r|$

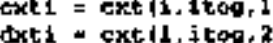

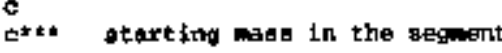

tent $=\operatorname{cxt}+$ vol

c*n. masa kransfer with frocturt zon

12 icfrac $\{1,1\}$. nt. a. I then

dit n otxacil.1) afracil

al so

andif

it tefracit, al . no. 0. then

dat - crracti, 2 , afracil

- 120

daf $=0$.

$+$

advoctiondalfktwion wth next lowor cell

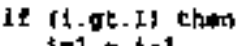

$$
\begin{aligned}
& 101=1-1 \\
& \text { Audle-dinct } \\
& \text { Amal 17-datax } \\
& \text { else }
\end{aligned}
$$

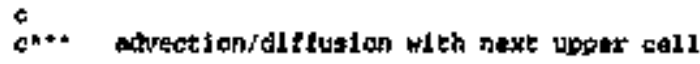

\section{it (1.1e.111w) then}

c... noter Eull upetrean waighting is used. witholt

wpgrath welohting, thase equations vould

Ge* [exti+cxtilpI, ftoolli/2. in place of

exti or cxe (ip1, itogl--that 11, the

contentration at the Intintace wowld be

the surrage fingtent of the upstream value

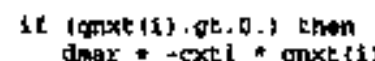

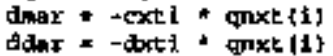

else

doax = -ext [ipl, 1kog, 11 * gmekit

ddax $n$-ext $\{(i p l, 1 \cos , 2\}+\operatorname{con} x t(i)$

\section{indif $f$}

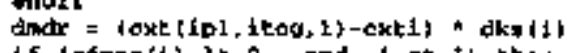

c..t if the current cell has an out 1100

car adrection wase in llows out to outflon las mach as

c

1f (anxt (1-1),gt.0.) then

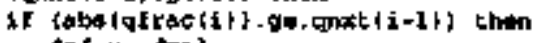
inf I- - dmal

if codal 0.1 be - the -

$\bullet 1$ as

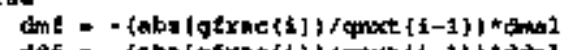

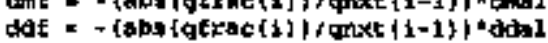

if 1 datiot.o. 0 . endilf endie

if (encex $\{i\}, 12,0$.$\} then$

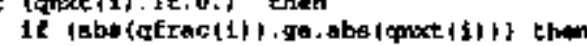
$\operatorname{dm} E=\operatorname{dinf}=\operatorname{din} x$

if idudr.ge, 0.1 dent $=$ ant - dendr

else

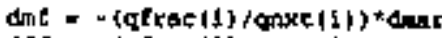

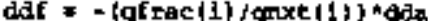

if andr.gt.0. ondit

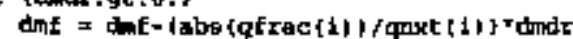

the*de1t ndite 
elвe

hatre0.

dintre0.

cas outflow cotididerea only at top ino masa flow back in at top

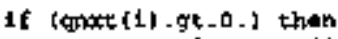

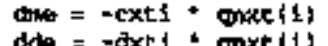

elae

$$
\begin{aligned}
& 11 \text { ionxti1).1k.0. I then } \\
& \text { dde } x \text {-topd * onxt i } \\
& \text { endif if }
\end{aligned}
$$$$
\text { ondif }
$$

$e^{n+n}$ check for segment mass 1imftatlons

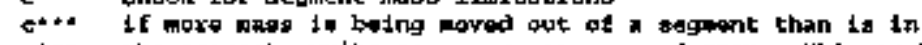

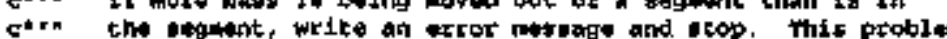

$e^{n+n}$ tan be fixed by redueing the tine stow or inereosimg the

enth degment length

\section{Itiso $=0$}

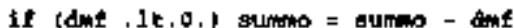

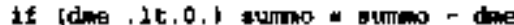

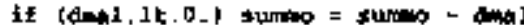

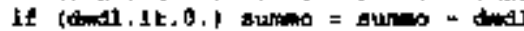

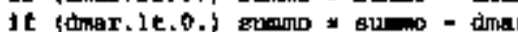

if toindr, lt, 0.1 sumbno a sum - dmate

far* atrempted to tranater more than 105 mags out of the coll

c

otep i" too big

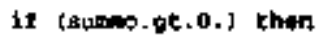

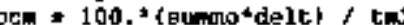

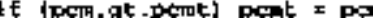

1t ipen.gt 100) then

$t=100 . / p c m$

if ffit. foctl fack a

mal

entil

ce.. conputa now magk in gegment

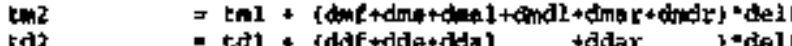

$$
\begin{aligned}
& \text { Ed - tdil * iddf +dde*dkal tddar } r \text {-delt } \\
& \operatorname{cxt}\left\{f_{1}\{t o g x, 1\}=\operatorname{tm} 2 /\right. \text { wol }
\end{aligned}
$$$$
\text { OחAdo }
$$

c*th tok sarw of outlowa tren cell llik (top)

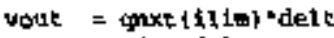

$$
\begin{aligned}
& \text { mout = - dmatalelt } \\
& \text { actoost } x \text {-datedelt } \\
& \text { it 1ane.1k.0.1 thon } \\
& \text { gtmont - gtmput + vouts (topm/ topp } \\
& \text { topr a tora = vout * t tognd topv } \\
& \text { kopm a topan anout } \\
& \text { endit }
\end{aligned}
$$

gtdout $=$ gtdout + vout topd
E wrike touk, *' 'gtabut*', gtdouc

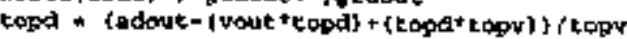

ge vout $=$ gtyout + vout

if dade.gt. D. then

din = -vouk $*$ topho

gtdina a grdire + aln

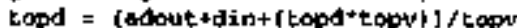

gtvins = otvina - vout

endif

c.t. End of loop over segments

chan it the mass trangfer is good ttime step not too bipl.

16 (1tsilk. aq. o) Eham

ent+ add mast to fracture sone volumes 11 necessary

Ao i=1.iflin

[ Ifin\{f\}, kt, of them

v15 = abs (ain (d) rdelt)

cil I gfeass [itaegili)/vil

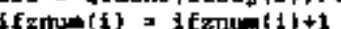

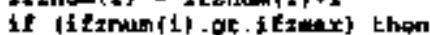

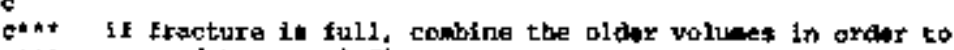
$\mathrm{c}^{\mathrm{nt}}$ accopodate more infion

$$
\begin{aligned}
& \text { do jni, ifzuax } \\
& \text { \{j., 䊉-1) thon }
\end{aligned}
$$

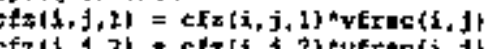

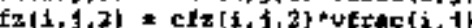$$
\text { 1.t. }
$$$$
\text { if if.10.10\} then }
$$$$
\text { cfz }(1,1, a)=\operatorname{ctc}(t), t,
$$

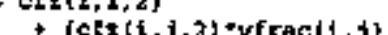

lo$$
\text { se }
$$$$
\begin{aligned}
& \operatorname{cfz}\{i,\{j-9\}, 1\}=\operatorname{ctz}\{1, g, 1\} \\
& \operatorname{cfz}\{1,\{j-9\}, 2\}=\operatorname{ctz}\{1, j, \lambda)
\end{aligned}
$$$$
\text { and } f
$$$$
\text { vrrac }(i,\{j-9\})=\text { vfructi,j\} }
$$

madp

ef $11,1,1]=\operatorname{etz}(1,1,1), \operatorname{vfrac}(1,1)$

etx $\{1,1,2]=$ eff $[(i, 1, a, /$ veract $(1,1)$

Itzrum(1) = 2tznax-B

endit

tank tranater to frocture

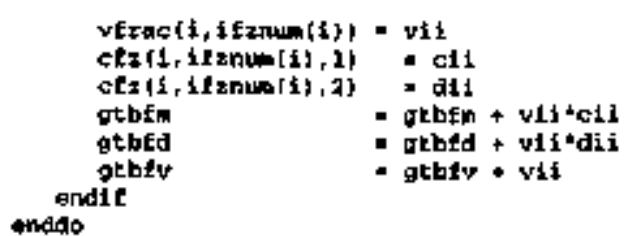




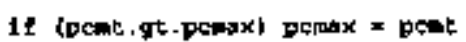

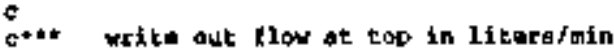

chrs $=\mathrm{t} / 3600$

al anut $\{111 m\} \div 60000$

$1=2$ gtwont 1000 .

itat topite rom pointer

ikogkikogx

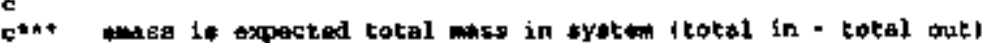
cont. gkm is actual total mast is systom

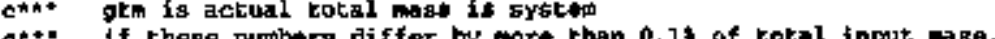

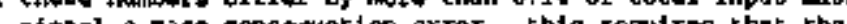
ather

rumerleal accuracs of all the alscrate maso calculations be

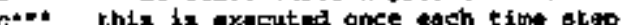

call ama日e

get + tom

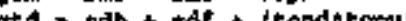

if Itrmalane. o.t the

$\ddot{6}$

masga itmo + tme

Arm $[100 *$ *

it abaterrol. gat 0.1$)$ then

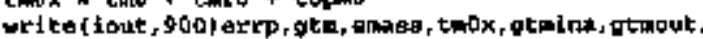

$$
\text { mito }
$$

emale

if tgtaina, he, 0,1 thit

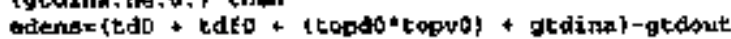

errdegtd-edens

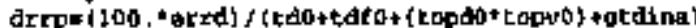

If (absidure) .gt.0.1) then

tdox - tato + tdfo + (tood $0^{n}$ topwo)

write! iout. 920\} arro. gta, edend, kdox, atdina, atdout.

$$
\begin{gathered}
\text { gtoo } \\
\text { Endif } \\
\text { Ordif }
\end{gathered}
$$

c alse

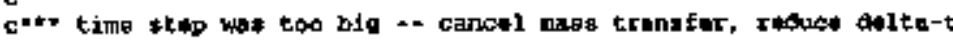

$$
\text { dalt = delt } 0.5 \text { - ielelt + tect }
$$

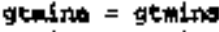

vtalin = gtatno

gtruat = gtmats

gtout = grdos

StbEm - gtbims

gtrom $=$ gtempin

gtvina $=$ gtvins

gtwout * gtwol

Dthiv $=$ DthEv

gttby $=$ atsws

restore frecture valusa it the time step is too big

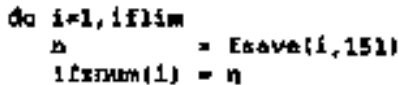

1iriven (1) :

if (n.gk.o\} then

do $y=1, n$

vfrac(t,j) = Enave $\{t, j)$

cEx $\{(t, j, 1)$ fatre $(1,(j+0)$

cf $\{1, j, 2\}=$ Eave $\{1,\{j+\pi\})$

enderso

ondir

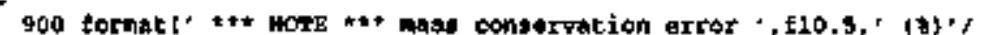

obeerved mags in syetwe (kg) : ', $20.5 / 1$

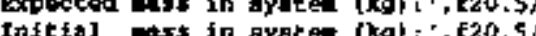

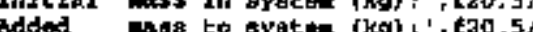

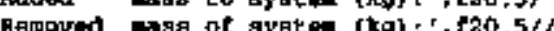

hant in bor thole (kg) (kp) ?

Hass in fracturen $\{\mathrm{kg}\}$ :

Hags in top $\{\mathrm{kg}\}$ : $\quad r, \pm 20,5 /\}$

910 format $\{2 \mp 13.6$

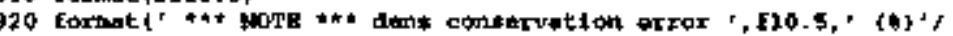

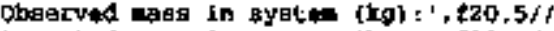

Expected nasa in aysta $(k a): r, 120.5 /$

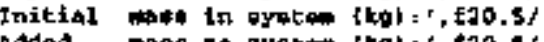

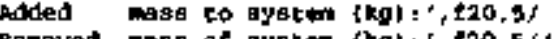

Renoved mase of aysten (kal : r, 220.5/t

Nass in borthol* (xy): $\quad$ r,f20.3/

Mass in top $(k g)$; ( $\mathrm{kg}$ )

ind

aubroutine flomess

c*.. trac holda the multipliera tor Bchemes 2 and 3

C ipliete doublo procition (a-h

implicit doublo profision $\{0-2\}$

include 'vpcopute $E$ '

c.nt compute flow up to next begrent and total flow

a $\{=1,111 m$

if $[1 . \mathrm{Ag} .1]$ then

qtot (1) atrecti

10

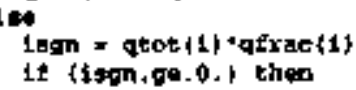

qtok $\{1\}=\operatorname{abs}(\operatorname{anxk}(1-1)+$ qtrac $[i]\}$

Glso

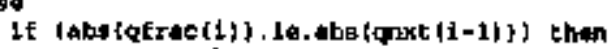

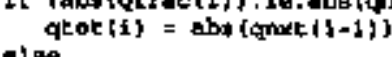

alee

atif

atoc (1) - abs (atrac (i)

andis 
c". computa flow to next cell up the hole. quxtillhm is flaw ctr. out of tintol the cos of the section

$$
\text { andif }
$$

cto

c** colmpute maximain time step and Rompld's number

qtmax $=\operatorname{stot}\{1\}$

do $1=2,111$.

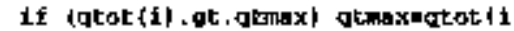

endiso

voax a qumaxiaren

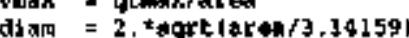

anace $=$ imention $0.30-6$

the = delt $/ 60$

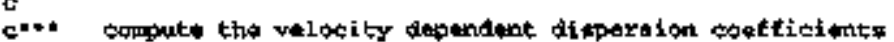

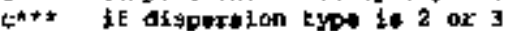$$
\text { if (1typdk.gt. } 11 \text { then }
$$

c.. Lind tirst nomzero, minloura, maximas and mean volocities

㠿

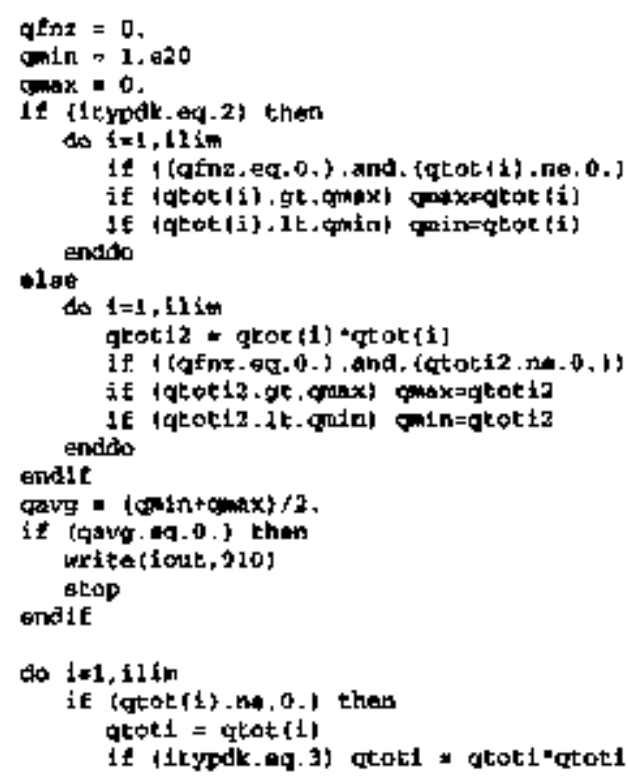

c'.. use tirsk nonzero flow for zera flow ared

$c \quad$ elso

$$
\begin{aligned}
& \text { else } \\
& \text { endif } \\
& \text { tracil) - qkokisqavg }
\end{aligned}
$$$$
\text { andido }
$$

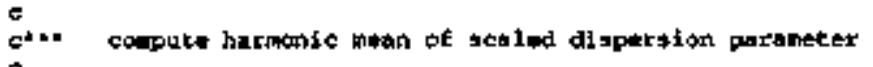

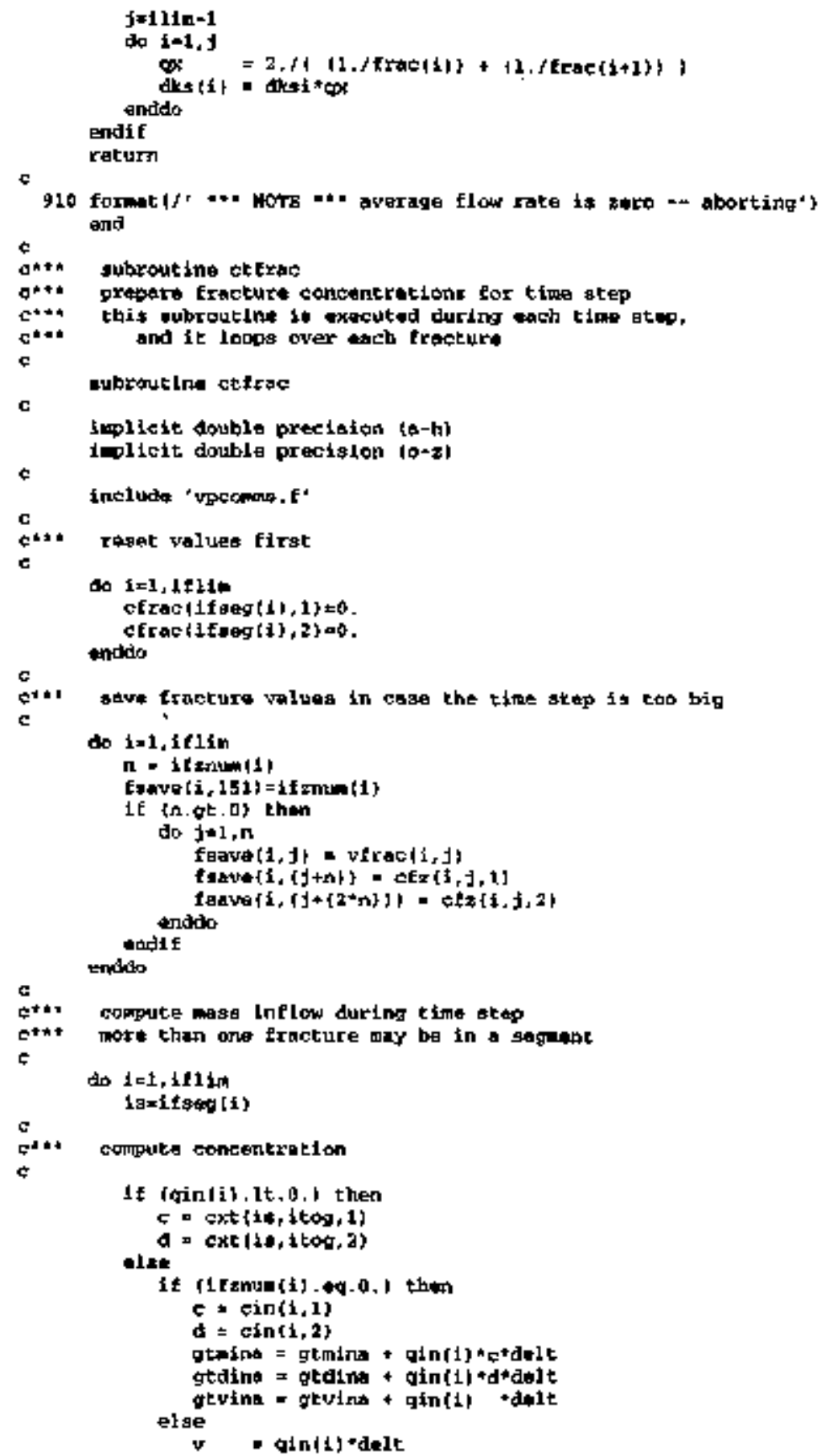


500

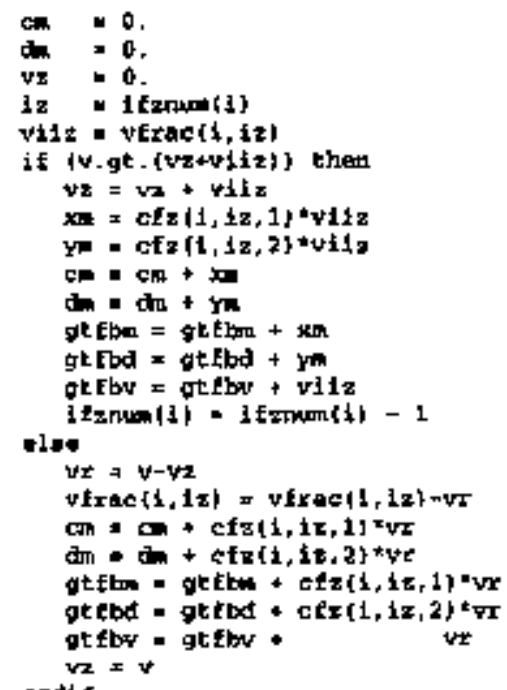

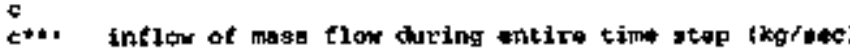

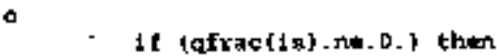

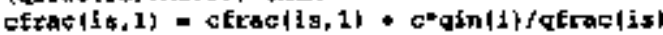

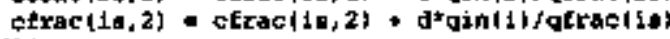
andit roturn

c*n* eubrouting ditione

cit. calculate Elows through each seraent

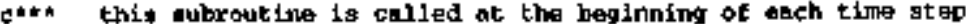

gubroutino allow

inglicte double prectolon ta-h

implict double procision to-2
Include reconsan ,

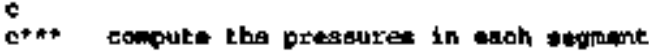

wlold = metes

matleve = matlevo

if it, gtandotidaraw)

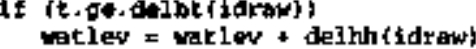

entito

If (watlev.ne.uloldl then

do = iwlold - wat lowi n aripk

du \& iwlold - wat

if idv.1t.0. $x$ then

gemont = gknout - im

gtmout = gtenout - do

gtadut - gtdout - (ditrtopa)

1 1s*

topam $=$ topy $\cdot$ topd

topd = topdis t (topy + du

and $f$

eopv $=$ (xtop-mat tevi tares

Axz $=$ elel $x / 2$.

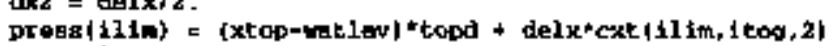

os $j=\{1\{1 \mathrm{fn}-1\}, 1,-1$

press $\{1\}=$ pregs $(t+2)$.

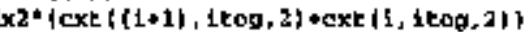

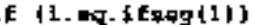

ando

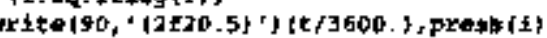

$c$

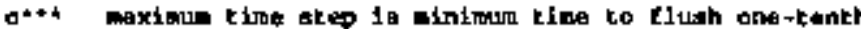

c.1. of a segunt. note that thile timp ray atill be too large

c*th it al sparalon to ongniflcant

It IIfilte.eg.01 thon

If totmax.ru. 0, than

If (delt, gkt, temsx) delt - tomax

0100

and $=0.01 \div \tan x$

encilt

cine initialize squment trows
do tel, tlim
Qfrect1) $=0$.

endero

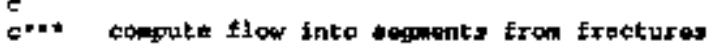

c*ax it is go*sible to hava mero than ome fracture in a single itht obgmant

al $1=1,2 \mathrm{t} 1 \mathrm{~m}$

c*t. cempute flon rate as a tunction of pressure arop $\operatorname{ain}(1)=0$.

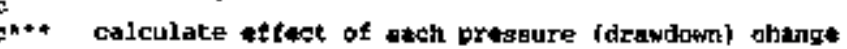


if (ipliand1, oq.0) then plim(i) 2

Dhet $(1,1,1)=$ hfrate t

jhits $[1,1,2]=-1,+20$

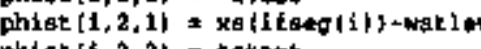
endit

it $t$ (i, $21=$ terart

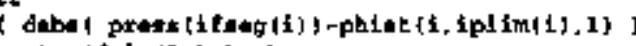

- vt. (t) $=1 \times / 2+3)$ thom

if (iplin(f) gt, notios) the

mitaldout, "l 'Hax iplin 1s', nodes, "-aborting

Ao illel, spdpe

$$
\text { andido }
$$$$
\text { stop }
$$

endile

bblatid, fDlin(1), dh a progsidfeeg(i)

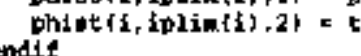

cons

ote: if preesure change occura exactly on a

th otep boundory, there is no togut

do tpez, iplimil

战e

c.e. calculate effoct of chonge betwean timut

14 it. ge.phiacis, ip. aj) then

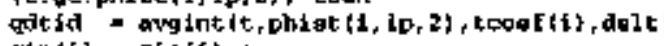

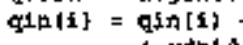

eqdiele qeontili.

$$
\begin{aligned}
& \begin{array}{l}
\text { expdif } \\
\text { andab } \\
\text { atractit }
\end{array} \\
& \text { endido }
\end{aligned}
$$

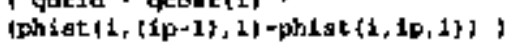

$c$

c.*. determint offective ahmanalonlase flow rete for timo step double precial on tunctios avgint (t, tp, teoof, delt) inolicit double presision $(a-h)$

c divension Ls t101\}, gsilur,

c... first ehopek anfipointt

г.

writel6, 998, it/3600, 1, (to/3600, l, delt

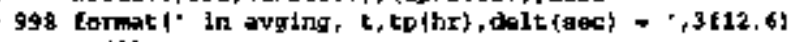
tB(1) $\quad x \mathrm{t}-\mathrm{tD}$

ad (1) adtesi1\}*teoef

$\operatorname{cota}=\operatorname{ta}\{1\}+\operatorname{do} 1 t$

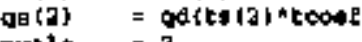

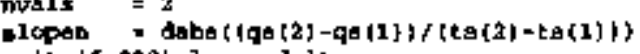

- vr1tef6, 999\}alopen delt

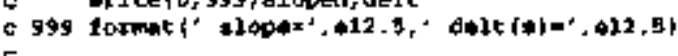
if (Blopen.gt.1. $0-2$ \} Chen
mralg $n$ iol

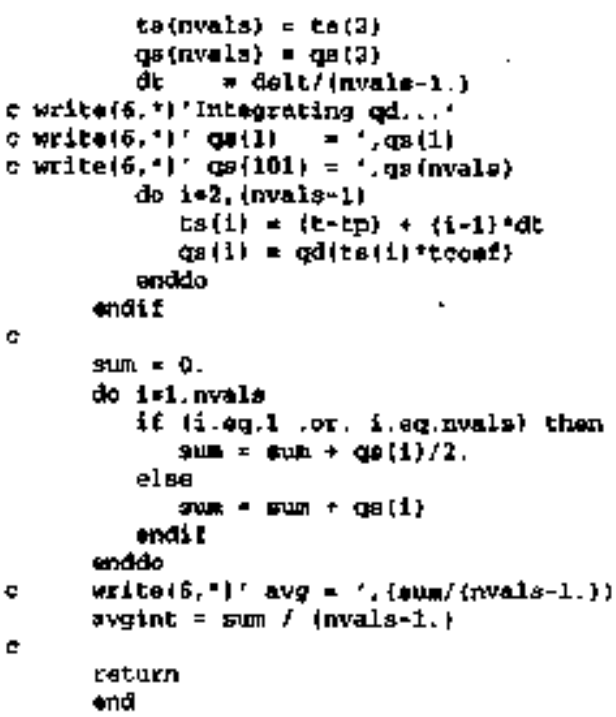

ind

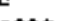

c*a

et+.

caxt

cat.

$\epsilon^{* *}$

$c^{n k \hbar}$

$c^{n+n}$

cot*

cin

c*tak

c*at

cit:

c*to

c**.

con

chis

$c^{*+1}$

c*t.

cers

$c^{* x+\infty}$

co...

ct*

c***

c*t+

$c^{+\infty+\infty}$

c time.

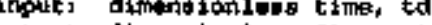

dimensionless tlos rste, qa

ange: $1.4-4=$ td $\alpha=1.912$

August 1932. pp. \$59-569.

double precteion function qdital

plicit dpuble preciston $[\mathrm{e}-\mathrm{h}$

almansion gdtaidisi, tod (143)

, ga la get to firát value In cabl.

cod 18 set to one endoolnt valut, and

soletion nethod: kable lookw and linear interpolation

Honeteady flow to a woll of constent drawdom in an

extanalve aquiter. by C.E. Jacob and S.w. Wohean.

olution bethod: Altwet muerical approxination

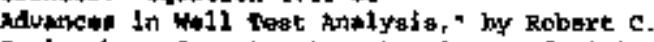

Earlougher, Jr. Amorlean Enstitute of kining,

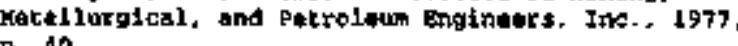


data adt

$96.9,40.4,33.1,28.7,25.7,23.5,21,6,20.4,19.3$ 8, 34,13,12,10.79, 9.42, 8.47, 7+77, 1.23, 6.79, 6.43,

$6.13,4.47,3.74,3.10,3.00,2.79,3.60,2.46,2.15$

$2.249,1.716,1.47,1.333,1.231,1.160 \times 1.103,1.057,1.018$

$0.983,0,003,0,719,0.667,0.630,0.602,0.580,0.562,0.547$

$0.533,0.461,0.137,0.405,0.389,0.317,0.367,0.359,0.352$

$0.348,0,311,0,294,0,283,0.274,0,260,0.263,0.238,0,254$

$0.251,0.232,0.222,8.215,0.210,0.206,0.203,0.200,0.298$,

1964, . 1041,..1779, , 1733, .1201, , 1675, , 1654, . 1636, . 1521

$1608_{r}, 1324, \ldots 149, \ldots 109,, 1426,1408_{r}, 1393, .1360, \ldots 1369$

$1960, .1299, .1266, .1246, .1227, .1213, .1202, .1192, .1184$

$1177_{r}, 1131, .2106, .1089,, 1076,1066,, 1057, .1049_{r}, 1043$

.

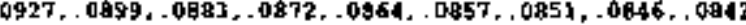

0838, .0814, .0801, , 0792, .0785, .0779, .0774, , 0770, .0767

$0764,0742,0733,0726, .0720,0716$, 0722,.0709, .0706, .0704

data tde

$1,0-4,2,0-4,3,8-4,4,4-4,5,8-4,6-8-4,7,0-4,0,0-4,9,0-4$

$1,4-3,2,0-3,3,0-3,4,0-3,5,0-3,6,0-3,7,0-3,8,0-3,9,0-3$,

$1 .-2,2, e-2,3,-2,4, e-2,5, e-2,6, e-2,7, \bullet-2,8, e-2,9 . e-2$

$1,0-1,2, *-1,3,0-1,4,0-1,5,0-1,6.0-1,7,0-1,8,0-1.9,0-1$

$1,40,2.00,3.40,4.40,5.40,6.40,3-\infty, 8.4,9.40$

1.e1, h.e1, 3.e1, a.e1, 5.01, 6.e1, 1.e1, e.e1, \$.e1,

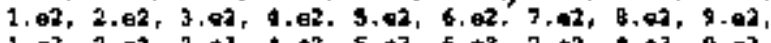

$1.03,2,83,3,43,4,43,5,43,6.43,7,43,0.03,9,63$,

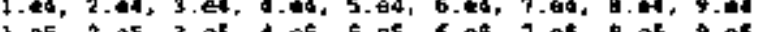

1.es, 2.es, 3.es, ties, 5.e5, 6.es, 7.es, g.es, 9.es,

$1.46,2.66,3.06,4.96,3.46,6.06,7.46,8.06,9.66$,

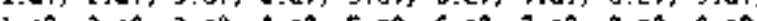

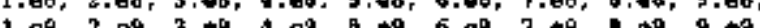

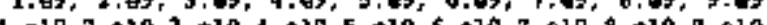

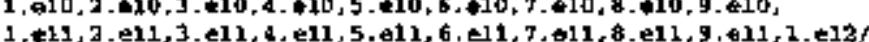

e

loat $=5$

c*.. eheck range of tol

le (tod, le. tod [ [ ') then

gatome \pm qdtail

getrt wse amalytieal golukion for large values

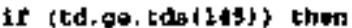

quterg $=2 . /$ (alog $(t a)+0.80907)$

c*it conpute Indices dnto table

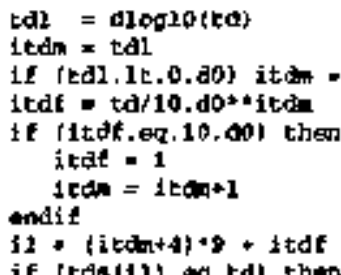

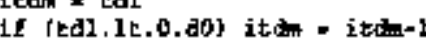

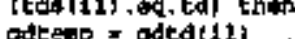

c*** 1ntarpolate tablo

$$
\begin{aligned}
& \text { it itd.1t.tds(11) } 11=11-1 \\
& \text { lf (td.at. } t d p(11+1)] \text { if }=11+1
\end{aligned}
$$

ie (11.1k.1) $11=1$

If $(11.96 .145)$ i1 $=145$

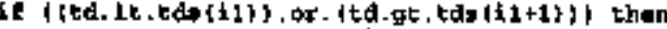

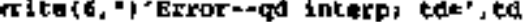
else 180

lope - Iqdta(1]+1)-qatalíl1)

delx - ted - tod (11)

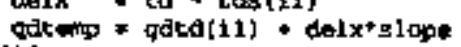
endic

qd - qdteos

rotum 